OPEN ACCESS

Edited by: Lalit Pandey,

Indian Institute of Technology

Guwahati, India

Reviewed by:

Ashwini Chauhan,

Tripura University, India

Himansu Sekhar Nanda,

Design and Manufacturing, India

*Correspondence:

Jayesh R. Bellare

jb@iitb.ac.in

Specialty section:

This article was submitted to

Biomaterials,

a section of the journal

Frontiers in Materials

Received: 14 August 2020

Accepted: 27 November 2020

Published: 18 February 2021

Citation:

Preethi A and Bellare JR (2021)

Tailoring Scaffolds for Orthopedic

Application With Anti-Microbial

Properties: Current Scenario and

Future Prospects.

Front. Mater. 7:594686.

doi: $10.3389 /$ fmats.2020.594686

\section{Tailoring Scaffolds for Orthopedic Application With Anti-Microbial Properties: Current Scenario and Future Prospects}

\author{
A. Preethi ${ }^{1}$ and Jayesh R. Bellare ${ }^{1,2 *}$ \\ ${ }^{1}$ Department of Chemical Engineering, Indian Institute of Technology Bombay, Mumbai, India, ${ }^{2}$ Wadhwani Research Center for \\ Bioengineering (WRCB), Indian Institute of Technology Bombay, Mumbai, India
}

Research in the orthopedic application has attracted the scientific community to design and develop advanced, engineered synthetic scaffolds that possess all the essential cues properties necessary for successful regeneration and restoration of tissue function. Despite having the best surgical practices, nosocomial infections like surgical site infections can negatively impact the outcome of the scaffolds that are intended only for regenerative purposes. Therefore, there is a need to include antimicrobial properties as one of the parameters while designing a scaffold. There are various methods implemented to tackle microbial colonization such as modifying the scaffold surface that deflects microbes from surface adhesion and modifying the scaffold surface by inactivating microbes upon contact while maintaining the biocompatibility of the scaffold and also maintaining the scaffold viable for new bone formation. This review lists various anti-microbial polymers and compounds available in nature and methods to incorporate them into the scaffold with polymer and ceramics as the base material, without compromising bioactivity. We have reviewed various antimicrobial compounds, biomaterials and have also identified various biomolecules (vitamins, phytochemicals and anti-microbial peptides) that can be utilized for orthopedic application.

Keywords: anti-microbial property, biocompatible, biomaterial, resorbable, scaffolds, orthopedic, tissue engineering

\section{HIGHLIGHTS}

1. Antimicrobial action can be from added nanoparticles, chemicals or chemical modifications on the polymer.

2. Metal, ceramics and carbon based nanoparticles and their modification in the scaffold are identified.

3. Phytochemicals, vitamins and anti-microbial peptide with anti-microbial properties are reviewed. 4. Possible chemical modification of polymer with innate anti-microbial properties are discussed. 


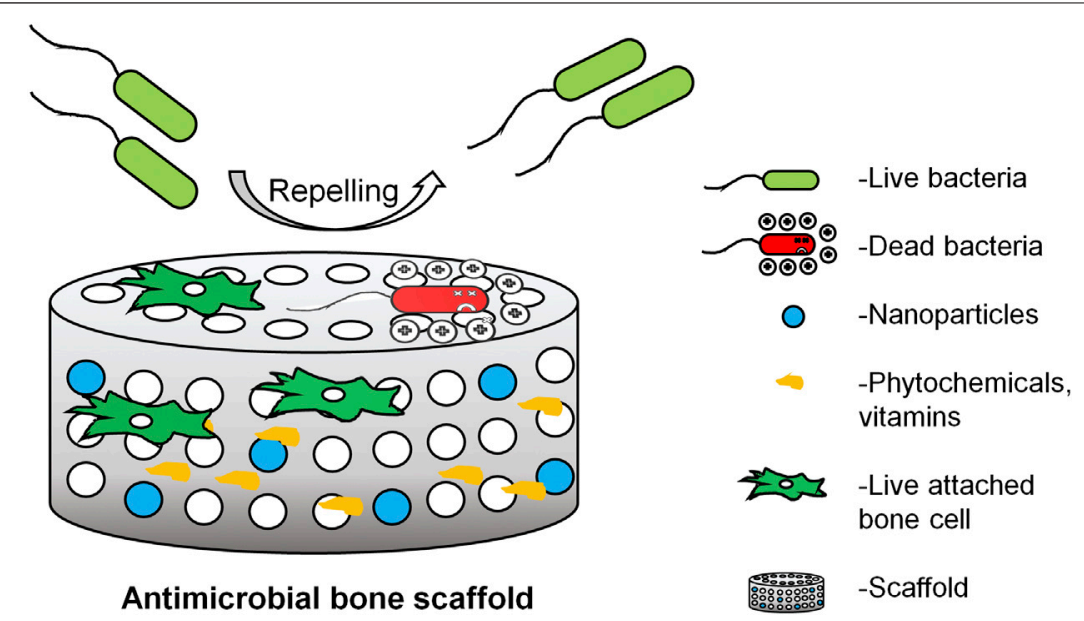

GRAPHICAL ABSTRACT |

\section{INTRODUCTION}

With 2.2 million bone graft procedures performed per year, bone becomes the second most transplanted tissue followed by blood (Kashte et al., 2017). Even though autografts were considered the "Gold standard", their availability, donor site morbidity, and increased risk of infection has made researchers to seek for alternative materials that fulfill the advantages autografts possess. Over the years, the design aspects of synthetic grafts have been modified to incorporate the requirements of the grafts that they are intended for. 1) Initially, the synthetic graft was meant to serve the mechanical needs of the host tissue but not to interact with them. Metals like titanium and its alloy, polymers like PMMA, PEEK, and ceramics like alumina and zirconia were used. 2) Then, the material design of synthetic graft was further modified by incorporating bioactive compounds like calcium phosphates, calcium sulfates, along with polymers that degrade with time in vivo that includes synthetic polymers like PCL, PLGA, PGA, PLA, etc., and natural compounds like gelatin, collagen, and bioactive glasses were used. 3) Later, it was further modified by incorporating growth factors like compounds and compounds that modify according to external stimuli (Qu et al., 2019). Based on the evolution of synthetic graft's design requirement the scaffold can be defined as a three dimensional template that provides biophysical, chemical and mechanical stimuli essential for successful tissue regeneration, restoration and function.

United States faces approximately 500,000 surgical site infections per year. $25 \%$ of open fractures have a risk of infection based on severity of fracture (Schmitt, 2017). This may result in complications like non-unions or delayed unions of bones (Lee et al., 2015). Osteomyelitis (bone marrow inflammation) is predominantly caused by $S$. aureus in bone. Other microorganisms frequently involved are $P$. aeruginosa and methicillin resistant $S$. aureus (MRSA), S. epidermidis, E. coli, E. faecalis, E. faecum. $30-60 \%$ percent of infection is caused by Staphylococcus aureus (Hofstee et al., 2020). Osteomyelitis can be caused through 1) infection spreading through blood stream, 2) infection spreading through adjacent focus of infection and 3) diabetic foot infection (Brit et al., 2017; Schmitt, 2017). The general treatment involves surgery i.e., aggressive debridement of necrotic tissue followed by antibiotic therapy. Antibiotic therapy involves vancomycin, ciprofloxacin, cloxacillin, gentamycin, clindamycin, and/or their combination through the intravenous route (del Pozo et al., 2018). In most cases, nosocomial infection, an infection caused by organisms from skin flora as a result of fracture, diabetics, are more prevalent in causing osteomyelitis (Schmitt, 2017). $25 \%$ of open fractures have a risk of infection based on how severe the fracture is (Schmitt, 2017).

Even with the usage of appropriate surgical techniques, pre and post-operative procedures, all the orthopedic and related surgeries are at risk of bone infection. There is about $20-30 \%$ relapse of osteomyelitis, even after surgical debriment and/or anti-microbial therapy for 4-6 weeks (Bhattacharya et al., 2013). Due to insufficient blood supply, the required amount of antibiotics does not reach the target site, also, biofilms are growing resistant towards antibiotics (Bhattacharya et al., 2013). Therefore, one section of research is focused on incorporating antibiotics or their cocktail into the scaffold that locally deliver antibiotics to the infected site. Some of the antibiotics incorporated biodegradable antimicrobial orthopedic scaffold are listed in Table 1. The diagnosis, classification, treatment for osteomyelitis are discussed elsewhere (Scherping and Aaron, 2007; Witso, 2014; Winkler, 2017).

Currently, the antibiotic loaded scaffold available in the market are OSTEOSET ${ }^{\circledast}$ T (Humm et al., 2014) containing tobramycin sulfate, STIMULAN ${ }^{\circledast}$ (Kallala et al., 2018) containing antibiotics like vancomycin, gentamicin or tobramycin and injectable bone substitute like CERAMENT|G eluting gentamicin (Drampalos et al., 2018). There are various scaffolds, designed to release anti-microbial agents on demand on the site of infection. Even if the microbe is dead, the presence of a dead microbe can still be a site for antibiotic resistant biofilm formation (Johnson and Garcia, 2015). But also, there is very limited studies on cytotoxic effects, long term effects of antibiotics eluting scaffold and its involvement in bone's regeneration 
TABLE 1 | Effect of antibiotics used in scaffold towards osteoblasts and microbes function.

\begin{tabular}{|c|c|c|c|c|}
\hline $\begin{array}{l}\text { S. } \\
\text { no }\end{array}$ & Antibiotics & $\begin{array}{l}\text { Polymer(s)/ } \\
\text { ceramic }\end{array}$ & $\begin{array}{l}\text { Effect } \\
\text { on biological function }\end{array}$ & References \\
\hline 1 & Roxithomycin & PCL/PEG & $\uparrow$ Anti-bacterial activity against S. aureus than E. coli. $\uparrow$ Viability of MG63 & Bai et al. (2020) \\
\hline 2 & $\begin{array}{l}\text { Minocycline } \\
\text { hydrochloride }\end{array}$ & PLA/collagen/HA & $\uparrow$ Anti-bacterial activity against $S$. aureus. $\uparrow P, \uparrow O D$ of hMSC. & Martin et al. (2019) \\
\hline 3 & Levofloxacin & PU/HA/silica & $\uparrow O D$ of BMSC. $\uparrow$ Anti-bacterial activity against $S$. aureus and E. coli co-culture & Kuang et al. (2019) \\
\hline 4 & Amoxicillin & Bredigite & $\begin{array}{l}\uparrow \text { Anti-bacterial activity against } S \text {. aureus and E. coli. } \downarrow \text { MG63 adhesion } \uparrow \text { amoxicillin } \\
\text { concentration }\end{array}$ & Bakhsheshi-Rad et al. (2018) \\
\hline 5 & Vancomycin & $\begin{array}{l}\text { PLGA/Bioactive } \\
\text { glass }\end{array}$ & $\uparrow P, \uparrow O D$ of hBMSC. Anti-bacterial activity against $S$. aureus & Cheng et al. (2018) \\
\hline 6 & Enoxacin & PLGA/Mg scaffold & $\downarrow P$ of $S$. aureus and S. epidermidis and $\uparrow \mathrm{P}$ of $\mathrm{NIH}-3 \mathrm{~T} 3$ and $\downarrow$ osteoclast and activity & $\begin{array}{l}\text { Li et al. (2016a), Li et al. } \\
\text { (2016b) }\end{array}$ \\
\hline
\end{tabular}

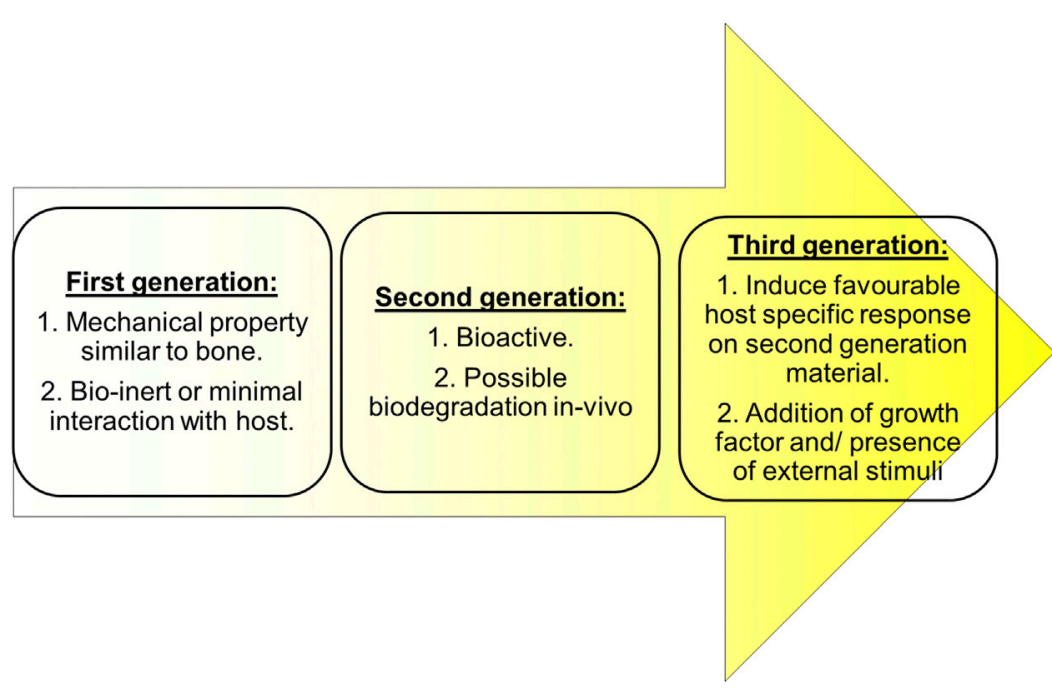

FIGURE 1 | Properties considered while choosing biomaterials for scaffold over generations (Qu et al., 2019).

capacity Figure 1. Therefore there is a need to design a fourth generation orthopedic scaffold that, also has anti-microbial property so that it not only prevents microbial adhesion, inactivates microbes but also reduces the need for antimicrobial therapy for long term use without compromising bone's regeneration capability. This review describes favorable factors of microbial and osteoblast interaction on the scaffold and the host, essential to describe a suitable biodegradable resorbable antimicrobial orthopedic scaffold design.

\section{SCAFFOLD DESIGN PARAMETERS THAT OPPOSE MICROBIAL ADHESION AND ITS MATURATION}

Design on degradable anti-microbial scaffold was aimed 1) to avoid external microbial ambush before implanting and 2) to eliminate established network of microbe in the host tissue.

Microbial adhesion on the scaffold surface is one of the complex multifactorial problems. External microbial ambush can be avoided by devising strategies that prevent microbial adhesion before it forms permanent bond with the substratum as in Figure 2. Microbial adhesion and biofilm formation on the surface has four stages: 1) transport of micro-organism to the surface, 2) initial but reversible binding to the surface, 3) permanent binding, and 4) colonization. The details of biofilm formation and cell to cell communication for both Gram-negative and positive species is discussed elsewhere (Arciola et al., 2018; Lu et al., 2019). Factors that determine microbial adhesion on biomaterials are 1) roughness and topography, 2) surface energy or charge, 3) hydrophilicity or hydrophobicity, and 4) chemical composition of the surface Figure 3. The following subsections will discuss the surface factors that can be tuned against initial microbial adhesion.

\section{Roughness and Topography on the Biomaterial Surface}

One way to reduce bacterial colonization is by providing less contact surface area for adherence. Many of the naturally 


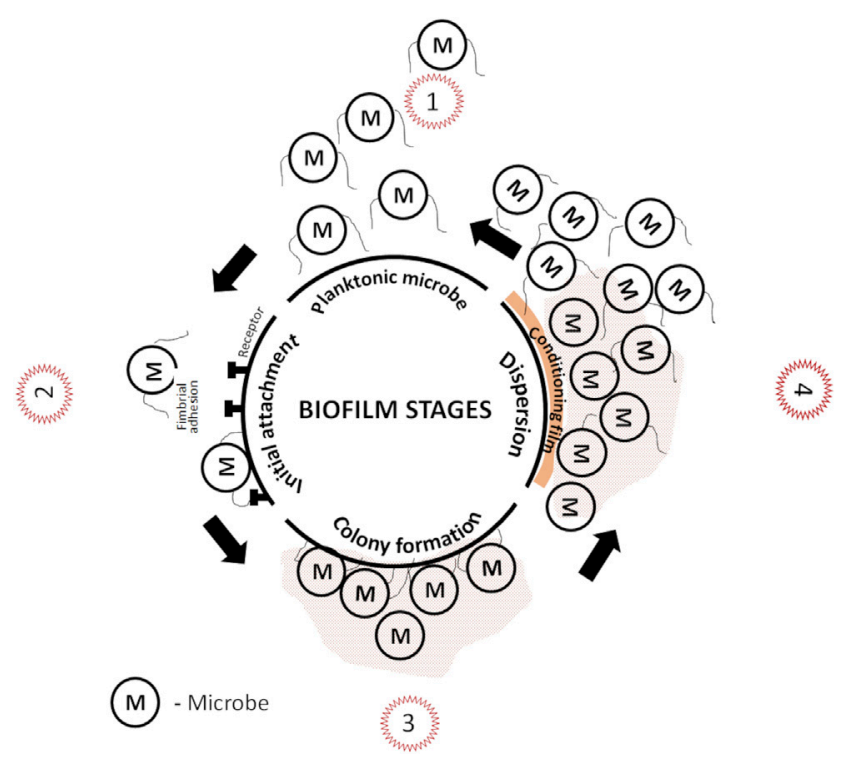

FIGURE 2 | Stages of biofilm formation.

available surfaces like Wings of cicada (Psaltoda claripennis), dragonfly (Diplacodes bipunctata), damselfly (Calopteryx hemorrhoidalis), taro leaves (Colocasia esculenta), and gecko skin (Lucasiuum steindachneri) has high aspect ratio nanostructures on their surface making them bactericidal on contact. Many studies have tried to mimic, evaluate and analyze the bactericidal efficiency of nanostructures arrangement and geometry. Such nanostructures were successfully implemented on the surface of various metallic and polymeric non-degradable implants. Bactericidal efficiency differs between Gram-positive and Gramnegative bacteria. Their difference in shape, cell membrane thickness, motility and plane of cell division, ruptures the cell membrane of bacteria that differentiates the nanotopography's bactericidal efficiency (Diu et al., 2014; Bhadra et al., 2015; Kelleher et al., 2016; Tsimbouri et al., 2016; Wu et al., 2018; Linklater et al., 2019). Studies on wrinkled patterns on polymer surface provide combinations of nano and microstructures that prevents microbial colonization (Nguyen et al., 2020). Scaffolds prepared through electrospinning provide roughness and topography essential for reduced bacterial contact.

\section{Surface Charge, Surface Energy and Wettability of the Biomaterial Surface}

The second mode of making an anti-bacterial surface is by utilizing materials with surface charge. Bacteria at biological $\mathrm{pH}$ have a negative surface charge. Gram-negative bacteria have a highly negative charge and hydrophilic surface in comparison to Gram-positive bacteria. The lipopolysaccharide renders Gram-negative bacteria a more negative charge than Gram-positive bacteria. When positively charged nanoparticles from metal and metal oxide are used, they get attached to the cell wall due to electrostatic interaction and they get pulled into the bacteria. These nanoparticles not only alters cell membrane's structure and permeability but also causes ion homeostasis, catalyzes proteins to inactive and produces reactive oxygen species (ROS) (Raghunath and Perumal, 2017). Similar to nanoparticles, polycations adhere to the membrane surface leading to membrane integrity disruption. In quaternary ammonium chitosan salts, an increase in the alkyl group rendered a strong anti-bacterial effect for both Gram-negative and Gram-positive bacteria (Rabea et al., 2003). The hydrophobic alkyl group got inserted or penetrated into phospholipid bilayer causing cytoplasmic leakage and cell death in E. coli and S. aureus. The presence of a cationic group in the main polymer chain has more anti-bacterial activity in comparison with side chain cationic polymers and small molecule cationic compounds (Guo et al., 2018). These mechanisms do actively kill bacteria.

Other mechanism is to passively drive away the bacteria from the surface. One way is to repel the bacteria by using negatives charged surface instead of killing them (Abbaszadegan et al., 2015). The second way is to delay bacterial adhesion is by using hydrophilic polymer brushes on the biomaterial surface and also by using a hydrophilic surface (Nejadnik et al., 2008). Pidhatika et al., 2010 used cationic hydrophilic polymer brushes to repel E. coli by providing both electrostatic repulsion and steric hindrance. Additional, factors that affect bacterial adhesion are temperature, time of exposure, bacterial concentration, the presence of antibiotics, environment electrolyte concentration and surface chemistry (Filipović et al., 2020). Similar concept applies to other microbes as well.

The above discussions focusses on the anti-adhesive properties of scaffold towards microbes. But the presence of fimbriae and flagella on the microbes plays a key role in overcoming all the 
TABLE 2 | Effect of vitamins towards osteoblast's function.

\begin{tabular}{|c|c|c|c|c|c|c|}
\hline $\begin{array}{l}\text { S. } \\
\text { no }\end{array}$ & Vitamin & Polymer(s)/ceramic & $\begin{array}{l}\text { Encapsulation } \\
\text { strategy }\end{array}$ & $\begin{array}{c}\text { Other } \\
\text { compounds } \\
\text { (if present) }\end{array}$ & $\begin{array}{l}\text { Effect on } \\
\text { biological function }\end{array}$ & References \\
\hline 1 & D3 & PCL & $\begin{array}{l}\text { Layered double } \\
\text { hydroxide }\end{array}$ & - & $\begin{array}{l}\uparrow P \text { and no significant increase in ALP activity of } \\
\text { MG63 }\end{array}$ & Belgheisi et al. (2020) \\
\hline 2 & & $\mathrm{HA}$ & PCL/PEG & - & $\downarrow$ Osteoclastic activity & Vu and Bose (2019) \\
\hline 3 & & PCL/gelatin & - & $\mathrm{HA}$ & $\uparrow P, \uparrow A L P, \uparrow$ early OD, $\uparrow M$ of hADSCs & Sattary et al. (2019) \\
\hline 4 & & Gelatin & $\begin{array}{l}\text { Layered double } \\
\text { hydroxide }\end{array}$ & $\mathrm{HA}$ & $\uparrow P, \uparrow A L P, \uparrow M$ of $G-292$ & $\begin{array}{l}\text { Fayyazbaksh et al. } \\
(2017)\end{array}$ \\
\hline 5 & $E$ & Poly(hydroxy butyrate) & - & Bioactive glass & $\uparrow P$ of $M G 63$ & Misra et al. (2009) \\
\hline 6 & & $\beta$-Tricalcium phosphate & PCL & - & $\begin{array}{l}\text { No coating on } \beta \text {-Tricalcium phosphate lead to } \\
\uparrow A L P \text { of } h F O B\end{array}$ & Bose et al. (2019) \\
\hline 7 & & Titanium & - & $\mathrm{HA}$ & $\uparrow P$ of $h F O B$ and $\downarrow P$ of MG63 & Sarkar et al. (2020) \\
\hline 8 & & $\begin{array}{l}\text { Poly urethane grafted } \\
\text { vitamin C }\end{array}$ & - & - & $\begin{array}{l}\uparrow P, \uparrow A L P, \uparrow c o l l a g e n-I \text { of osteoblast progenitor } \\
\text { cell }\end{array}$ & Zhang et al. (2003) \\
\hline 9 & $\mathrm{~K}$ & $\mathrm{HA}$ & $\begin{array}{l}\text { Poly xylitol sebacic } \\
\text { adibate }\end{array}$ & - & $\uparrow A L P$ and $\uparrow M$ on day 10 in MSC & Dai et al. (2019) \\
\hline 10 & $\mathrm{~K} 2$ & $\begin{array}{l}\text { PCL, gelatin, } \\
\text { poloxamer } 188\end{array}$ & - & - & Vitamin coated fiber has $\uparrow P, \uparrow A L P$ of SaOS-2 & Alam et al. (2019) \\
\hline
\end{tabular}

initial barriers between the cell and substratum (scaffold surface and/or animal tissue) and irreversibly attach. In host, microbes or it's colonies enter through iatrogenic or hematogenous routes and attachs to extra cellular matrix of bone by identifying adhesive molecules thereby forming biofilm (Hofstee et al., 2020). Similarly when a scaffold is inserted into host, the conditioning provided by the host can also be suitable for microbial attachment to the surface (De Cesare et al., 2019). Biofilms are established complex network of irreversibly attached microbes on substratum encapsulated by extracellular polymeric substances (EPS). Depending on the environment they are developed, biofilm may also contain non-cellular substances. The extensive details on EPS properties is discussed elsewhere (Donlan, 2002).

Bacteria's presence in host activates innate immune responses. Planktonic microbes are usually eliminated by phaogocytosis, oxidative bursts and by production of antimicrobial peptides, proinflammatory cytokines and chemokines. But microbial colonies has protective network that protects them from immune cells attack. Once a biofilm is established, they become impenetrable by immune cells and they start evolving, bone matrix becomes their nutrient source, osteoclastogenesis is promoted, inhibits bone formation thereby bone tissue loss (Hofstee et al., 2020).

For an established biofilm, changes in the physical properties like roughness and topographies of the scaffold doesnot affect EPS of biofilm. But EPS can be polycationic in case of Gram-positive bacteria and polyanionic in case of Gram-negative bacteria and EPS can be hydrophilic or hydrophobic (Donlan, 2002). Therefore, the scaffold have to be designed based on the organism that caused osteomyelitis. Usually, higher dose of antibiotic supplement on site using scaffold, but, biofilm tends to evolve. Therefore, these scaffold should be redesigned to possess all chemical elements that can penetrate and eliminate biofilm and also support osteoblastogenesis.

\section{SCAFFOLD DESIGN PARAMETERS THAT SUPPORT ORTHOPEDIC TISSUE ENGINEERING}

Tissue engineering on scaffold usually deals with mimicking the environment necessary for the successful restoration of tissue and its function. Scaffold for bone regeneration should be biocompatible, bioresorbable, biodegradable, should not create immunogenic responses, should have interconnected pores, it should support angiogenesis along with osteogenesis, should have strength similar to the original tissue along with the characteristics discussed in physical cues, so that it is anti-microbial.

Bone is a complex matrix and vascularized connective tissue that aids in locomotion. The chemical composition of bone can be classified into mineral phase and organic phase. The mineral phase of bone consists of hydroxyapatite and other trace levels of impurities like carbonates, sodium, magnesium, chlorine, fluorine, potassium, strontium, silicon, zinc, chromium, cobalt, and manganese. The organic phase consists of collagen I and non-collagenous proteins like osteocalcin, osteopontin, and alkaline phosphatase. Even though collagen I is present in abundance there are other types III, V and VI are present too (Neto and Ferreria, 2018).

Fabricating ideal scaffold deals with providing adequate, favorable biophysical, chemical and mechanical properties to manipulate complex interplay of various factors in the system towards the regeneration process. Physical and chemical properties play an important role in determining stem cell fate. Physical property that induce stem cells to differentiate towards osteogenic lineage and increase the activity of osteoblast that can be incorporated while designing scaffold are discussed here.

\section{Roughness and Topography}

Roughness and topography has a greater influence on directing stem cell towards osteogenic lineage and modulate immune cell 


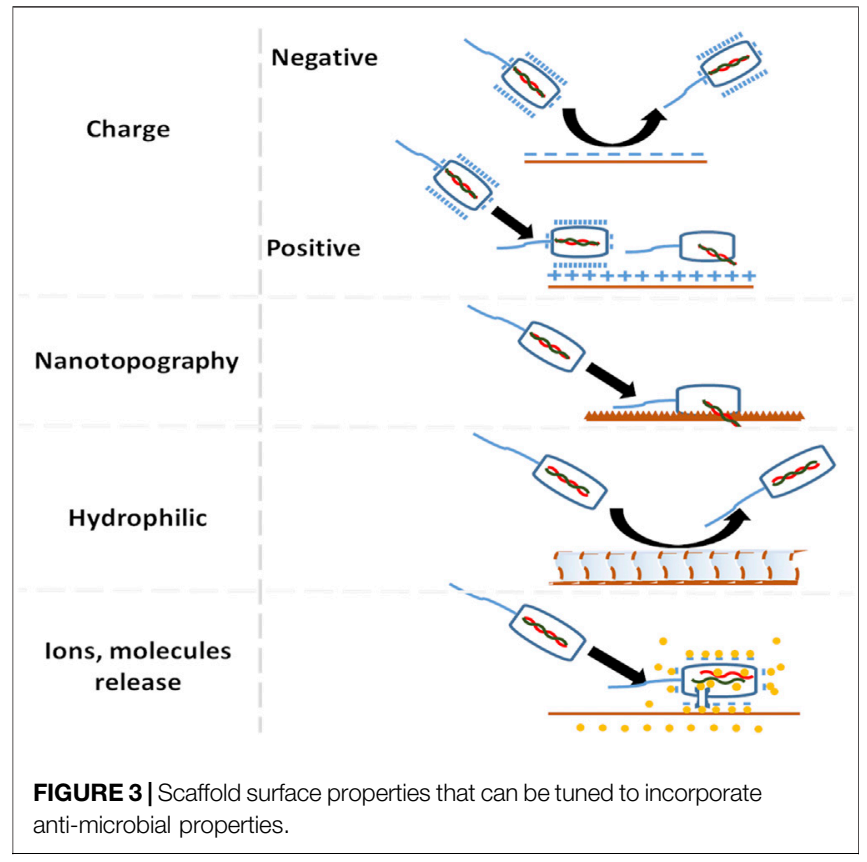

response. They are directly linked to the number of focal adhesion point which increases stem cell's stiffness and thereby increasing osteogenic expression (Yang et al., 2020). Micro/nanotopography that supports higher spreading area and giving rise to polygon like cell morphology supports osteogenic lineage commitment of stem cells. Similarly, a study on honeycomb like microstructure promoted osteogenic differentiation of hADSC (Zhang et al., 2020a; Zhang et al., 2020b). Additionally, nanotopographies regulate immunological response. Macrophages grown on the surface with grooves showed cytoskeletal structure reorganization and change in phenotype from M1 to M2 (Luu et al., 2015). Surfaces like nanotubes and nanofibers have also shown reduced inflammatory response by switching the phenotype of macrophages from M1 to M2 (Chen et al., 2017). Topography induced change in stem cell's stiffness showed biphasic behavior with respect to the degree of osteogenesis. hMSC cultured on the topography that supported osteogenic differentiation presented with higher focal adhesion area, higher cell stiffness triggered YAP translocation to the nucleus (Yang et al., 2020).

\section{Pore Size and Porosity}

Pore size, porosity and pore interconnection are one of the essential factors involved in scaffold construction. They are necessary for cellular infiltration, nutrient exchange, cellular waste removal and gas transport. Pore structure and size affects osteogensis and inflammation suppression (Zhu et al., 2020). Very small pores about $100 \mu \mathrm{m}$ supports cell adhesion and proliferation. Pores above $325 \mu \mathrm{m}$ supports cell migration. Pores in the range of $290-310 \mu \mathrm{m}$ exhibit faster bone formation (Dave and Gomes, 2019). Therefore, scaffold having hierarchial pore structure will cell adhesion, proliferation, differentiation and migration of stem cells.

\section{Degradation}

The term degradation in our context can be defined as gradual breakdown of a material mediated by specific biological activity by host. Similarly, the term resorption can be defined as elimination or completely absorption of degraded scaffold (Liu et al., 2017). Tuning scaffold degradation with bone remodeling is one important aspect in designing biodegradable and resorbable scaffold. Scaffolds undergo degradation when they are exposed to body fluids and the scaffolds properties changes as a result of chemical, physical, mechanical and biological interaction between scaffold and the surrounding environment. Degradation can be classified into oxidation and hydrolysis. These reactions may be catalyzed by acids, bases, salts or enzymes (Azevedo et al., 2005). Degradable scaffolds increase the pore size of scaffold with time for oxygen, water and cellular permeation (Dave and Gomes, 2019). Degradation also provides dynamic surface topography and roughness and regulates cell response.

\section{Surface Charge and Wettability}

When the scaffold is placed in the site of interest for bone regeneration, proteins get adsorbed to the surface from the blood within seconds. The surface on which the protein is adsorbed gives appropriate signals to recruit cells and perform a healing cascade. Adhesion of monocyte promotes local inflammation. Hydrophobic materials enhance whereas hydrophilic or neutral surface decreases monocyte adhesion (Jones et al., 2007; Hezi-Yamit et al., 2009; Chen et al., 2016a; Chen et al., 2016b). When it comes to surface charge, rat bone marrow mesenchymal stem cells cultured in basal medium on $\mathrm{LibNO}_{3}$, showed higher cell spreading and directed its fate towards osteogenic lineage on a positively charged substrate compared to a negative and neutral substrate ( $\mathrm{Li}$ et al., 2015). When osteoblast cell line MC3T3-E1 cultured on charged poly(ethylene glycol)-diacrylate hydrogel, proliferation and differentiation increased with increased for both positive and negative charge with higher surface charge density (Tan et al., 2018). This was because the mammalian cell membrane is neutrally charged and contains zwitterionic phospholipids, lipopolysaccharides, and lipoteichoic acid in its structure (Glukhov et al., 2005). Regarding apatite formation, initially, the usage of a negatively charged surface was preferred over neutral and positively charged surface when the study was conducted on polarized hydroxyapatite surface. The main reason being negative charge can attract $\mathrm{Ca}^{2+}$ ions and other proteins responsible for apatite formation and cell growth (Ohgaki et al., 2001). When a similar study was conducted on charged titanium surfaces, positively charged surface allowed apatite formation like their negative counterpart (Pattanayak et al., 2012) and bone has grown on the surface of positively charged titanium (Kokubo et al., 2010). But on the surface with no charge thin calcium phosphate layer did form but not as effective as charged surface (Pattanayak et al., 2012). Therefore, hydrophilic surface with high charge density supports cell adhesion and mineralization. 
KEY QUESTION: HOW TO MODULATE THE DESIGN PARAMETERS OF A DEGRADABLE SCAFFOLD THAT HAS A PREFERENCE FOR BONE GROWTH OVER MICROBIAL ADHESION?

Based on the discussion from "Scaffold Design Paramaters That Oppose Microbial Adhesion and its Maturation and Scaffold Design Parameters That Support Orthopedic Tissue Engineering" the following conclusion on the desired properties of a biomaterial suitable to support osteoblast adhesion along with antibacterial property, has been listed below.

(1) The roughness of the scaffold should be in the range of 0.2-2 $\mu \mathrm{m}$ (Hasan et al., 2017.

(2) Hydrophilic scaffold is preferable as it offers passive resistance towards microbes and better mammalian cell adhesion (Jones et al., 2007; Nejadnik et al., 2008; HeziYamit et al., 2009; Chen et al., 2016a; Chen et al., 2016b).

(3) Charges on the surface are preferred. The positive charge will give active bactericidal activity, negative charge will offer passive electrostatic repulsion. If the surface is zwitterionic (has both the charges but resulting in net zero charge), they produce a hydration layer that prevents bacterial adhesion by creating a physical and energetic layer (Vallet-Regi et al., 2020) and better osteoblast adhesion.

Generally, biodegradable and bioresorbable scaffold materials for bone tissue engineering scaffold can be classified into ceramics and polymers based on the base mater. To make scaffold with anti-microbial property, the following approaches can be followed:

(1) To use a degradable and resorbable base material of scaffold that possess anti-microbial property,

(2) By modifying the surface with a suitable charge/functional group that aides bone formation and repels microbes,

(3) By incorporating suitable nanofiller that enhances osteogenesis and/or bactericidal or adding filler that possesses all the desired property by surface or chemical modification of filler with ions or molecules and

(4) By blending or grafting scaffold with anti-microbial adhesive polymers or

(5) By using the combination of the above-mentioned strategies.

The following sections discuss about nanofillers, biomolecules, plant based extracts and biodegradable polymers that has both antimicrobial and osteogenic property.

\section{Scaffold With Metal Based Substitutions/ Fillers}

Other than the ionic and chemical makeup of bone, bone remodeling is a complex interplay of growth factors, signaling molecules, and cells. Growth factors included in the scaffold activates cascades of active bone repair, but they are associated with disadvantages like immunogenicity, instability, and high cost. To counteract the disadvantages, metallic ion or its oxide incorporation with or without incorporation of other ions and small molecules are investigated to make scaffold osteoinductive along with anti-microbial properties. Even though new antimicrobial drugs are researched, microbes can eventually develop resistance towards it. The optimal approach is to design scaffold that releases ions whose dosage and release kinetics support osteogenesis and eliminate microbes. Some of the ions are discussed in the section below.

\section{Ceramic Scaffolds}

Hydroxyapatite comprises $65 \%$ of bone mass comprises. They provide bone with high strength and toughness. The presence of ionic substituents in biological hydroxyapatites and their nano size makes them highly reactive and has the potential in maintaining ionic equilibrium in the body fluids (Ginebra et al., 2018). While designing ceramics like calcium phosphates, calcium silicates, and hydroxyapatites they are usually doped with ions that are responsible for increased osteoblast activity, angiogenesis, and anti-bacterial activity. Some of them are discussed in the table. Hydroxyapatites though osteoconductive they are not osteoinductive. Therefore the ratio of calcium to phosphate is modified accordingly to get better solubility. If the ratio is less than 1.5, the calcium phosphate has a higher solubility than hydroxyapatite. This was because, the presence of more phosphate ion makes the surrounding acidic, which eventually dissolves the ceramic e.g. the solubility of monocalcium phosphate monohydrate is highest with $18 \mathrm{~g} / \mathrm{L}$ in water at $25^{\circ} \mathrm{C}$ (Ginebra et al., 2018). Initially, the usage of hydroxyapatite in the scaffold was because of their presence in bone. But as research progressed, it was observed that this ceramic can house various element in their interstices and their ions can be substituted to give rise to a range of modified ceramic that can not only enhance the attachment, proliferation, and differentiation of osteoblast like cells but can also induce angiogenesis along with anti-microbial property. Other than the conventional substitutions like zinc, copper, silver, a new class of elements like molybdenum, gallium, selenium, bismuth, tellurium, samarium and cerium also found to possess anti-microbial property against both Gramnegative and positive bacteria and certain fungal strains too (The detailed explanation of anti-microbial activity will be discussed in the following section). Increasing metal ions attributed to microbial death, increased the anti-microbial activity but at the cost of mammalian cell cytotoxicity. Cytotoxicity of metal ion substitution depends on their extent to metal ion substitution, dosage and their release kinetics. The effect of different ionic substituents on the biological functions of ceramics towards osteoblasts and microbes is given in Supplementary Table S1.

\section{Scaffolds With Metal and/or Metal Oxides Nanoparticles}

As microbes grow resistant against antibiotics, the demand for alternative antimicrobial therapy that can replace the limited 
antibiotic options increased. Over the years it has been established that metal and metal oxide nanoparticles possess antimicrobial activity by the following mechanisms: 1) damaging the outer membrane by increasing permeability, disrupting electron transport chain leading to cellular content's leakage, 2) producing ROS to inactivate respiratory chain activity, and 3) DNA damage, thus disturbing gene replication of bacteria (Nostro et al., 2012; Pasquet et al., 2014; Thukkaram et al., 2014; Sirelkhatim et al., 2015; Li et al., 2016a; Li et al., 2016b; Mohan and Mala, 2019; Li et al., 2020a; Li et al., 2020b; Li et al., 2020c; Li et al., 2020d; Sánchez-López et al., 2020). They have diverse application in dentistry. For example, silver nanoparticles used in dental resin has good antibacterial activity against $S$. mutans and S. sobrinus (Foong et al., 2020).

Along with antimicrobial activity, nanoparticles serve multiple functions. They can be used to deliver bioactive agents, increase the mechanical strength of scaffold and with their controlled release from scaffold, nanoparticle can enhance biocompatibility, cell adhesion and proliferation.

Nanoparticles like, silver and silver oxide, copper and copper oxide, gold, zinc and zinc oxide, aluminum and alumnia, magnesium and magnesium oxide, Titanium and titania, zirconium and zirconia and iron oxide possesboth osteogenic and antimicrobial property. Among them certain metals like zinc and magnesium are responsible for increased synthesis of collagen, ALP, osteocalcin and matrix mineralization (O'Neill et al., 2018). Zinc is present in bone up to $39 \mathrm{ppm}$ and up to $10^{-4} \mathrm{M}$ in blood. Zinc is essential for bone metabolism, the paucity of zinc in the diet leads to abnormalities in bone growth, reduced bone mineral density, and might lead to osteoporosis in the later stage (Yamaguchi, 1988; Yamaguchi, 2010; O’Neill et al., 2018). The activity of zinc on osteoblast is dose-dependent. Zinc positively influences osteoblast in the narrow concentration of $1-50 \mu \mathrm{M}$, above this concentration they do not inhibit osteogenic activity but they become cytotoxic at a very high concentration of $600-900 \mu \mathrm{M}$ (O'Connor et al., 2020). Magnesium is present at about $0.6-0.72 \mathrm{wt} \%$ in bones. Dietary intake of magnesium increases bone mineral density and tougher bones. This was because the incorporation of magnesium in hydroxyapatites made the crystal size smaller but stronger (Orchard et al., 2014). Low magnesium reduces the function of osteoblast while increasing the number of osteoclast. It also creates resistance towards parathyroid hormone and $1,25(\mathrm{OH})_{2}$-vitamin D. Magnesium deficiency reduces antioxidant defenses, making bone brittle, fragile, impairs mechanical property leading to hypomagnesemia. But high magnesium content inhibits hydroxyapatite content by competing with calcium contributing to osteomalacic renal osteodystrophy (Castiglioni et al., 2013).

Metal and metal oxide nanoparticles at higher concentrations possess toxicity. Because of their small size, shape, charge and surface functional group these nanoparticles can diffuse across the cell or nuclear membrane, can be engulfed, disturb mitochondria and interfere in nucleus function thereby causing cytotoxicity and genotoxicity (Baptista et al., 2018; Lee et al., 2019; Wang et al., 2020). They donot undergo biodegradation, hence, their retention time is longer (e.g. some nanoparticle like copper donot get degraded by the body. They get accumulated in body causing Wilson's disease) (Varier et al., 2019).

These nanoparticle's antimicrobial and osteogenic activity can further be enhanced or the cytotoxicity of the nanoparticle can be reduced by doping it with other metal ions (Rao et al., 2013; Baptista et al., 2018; Saxena et al., 2018; Saxena and Pandey, 2020) that are present in bone and grafting biomolecules/polymer on its surface (Hasan et al., 2018). The extent of cytotoxicity can also be reduced by tuning the concentration, release kinetics of nanoparticle from the scaffold and their degradation. The effect of commonly used metal and metal oxide nanoparticles on scaffold towards osteoblasts and microbes function is given in Supplementary Table S2.

\section{Scaffolds With Carbon Based Fillers}

Carbon based nanomaterials has a versatile nature and has profound use in biomedical application. Their high surface to volume ratio, smaller size, modifiable surface charge, functional groups, wettability, their stability, and strength makes them suitable for bio sensors, drug delivery, tissue engineering and exhibit good anti-microbial properties. The following sections discusses about the anti-microbial and osteogenic potential of allotropes of carbon namely 1) carbon dot, 2) nanodiamond, 3) carbon nanotube, and 4) graphene.

\section{Carbon Dot (CD)}

Carbon dots are zero-dimensional material whose lateral size is below $10 \mathrm{~nm}$. CDs have carbon core and functional groups on the surface by surface passivation. Carbon dots can be easily and economically produced from any carbon source, either by breaking down large carbon molecules and polymerizing (topdown approach) or by carbonizing small molecules (bottom-up approach). The surface functional group can be introduced by using a carbon source that has the desired functional group and/ or by modifying the $\mathrm{CD}$ through hydrogen bond, covalent bonds and, electrostatic interaction. The common reactive functional groups are hydroxyl, carbonyl, and amine (Du et al., 2014; Liu et al., 2016).

In vitro CDs exhibited mild cytotoxicity above $80 \mu \mathrm{g} / \mathrm{ml}$ for preosteoblast and supported osteogenesis of preosteoblasts and faster bone formation with blood vessel formation in vivo through PERK-eLF2a-ATF4 pathway (Jin et al., 2020). Similarly, CDs exhibited mild cytotoxicity above $50 \mu \mathrm{g} / \mathrm{ml}$ for rBMSC and supported osteogenesis using ROS-mediated MAPK pathway (Shao et al., 2017). CDs also exhibit anti-microbial activity electrostatically interacting with the cell wall (Verma et al., 2019; Li et al., 2020a; Li et al., 2020b; Li et al., 2020c; Li et al., 2020d) and ruptures them, generates ROS (Verma et al., 2019) and also helps in eliminating mature biofilm. Their performance is on par with vancomycin (Wang et al., 2019a; Wang et al., 2019b; Wang et al., 2019c; Wang et al., 2019d). CDs antimicrobial activity was improved by coating with polymers like methyl polyethylene glycol/polyethyleneimine (Liu et al., 2020a; Liu et al., 2020b). 


\section{Nanodiamond (ND)}

Nanodiamonds have truncated octahedral architecture whose size is in the range of $2-8 \mathrm{~nm}$. They are inert, biocompatible, and can be functionalized, which makes them an ideal candidate to be used in delivering therapeutics and bone tissue engineering. NDs have shown good biocompatibility, osteogenic potential (Ibrahim et al., 2018) and anti-microbial property. Details of NDs osteogenic potential in various scaffolds is listed in Supplementary Table S3. NDs supports osteoblast adhesion over S. aureus (Rifai et al., 2019). NDs with negative or positive charge has shown antibacterial against $E$. coli and $B$. subtilis. This was because negative charged NDs penetrated bacterial cell, agglomerated and generated ROS because of the presence of high oxygen functional groups. Whereas positive surface charged NDs, attached to the surface of bacteria due to electrostatic force and caused little cell wall deformation making them less bactericidal (Wehling et al., 2014). Similarly, hydroxyl functionalized ND and its modification with menthol (Turcheniuk et al., 2015) and ND grafted with hydrophilic copolymer also showed anti-bacterial against E. coli and B. subtilis (Cao et al., 2018).

\section{Carbon Nanotube (CNT)}

Carbon nanotubes are one-dimensional allotrope, whose diameter ranges from 10 to $200 \mathrm{~nm}$. CNT can be single-walled or multiwalled. The ability to surface functionalize, excellent tensile property, and mimicking nanostructure makes them suitable for bone tissue engineering. Even though unmodified CNTs are relatively toxic, surface functionalizing and grafting molecules like HA (Song et al., 2019) or a polymer like gelatin (Yoon et al., 2014) that covers the surface to reduce its toxicity. In terms of anti-microbial property, surface functionalizing the MWCNT with - $\mathrm{COOH}$ by acid oxidation can delay the growth of $V$. parahaemolyticus but not completely deactivate it (Ding et al., 2020). But ethanol amine grafted MWCNT causes significant microbial toxicity. The order of toxicity was triethanolamine $>$ diethanolamine $>$ monoethanolamine along with it the triethanolamine grafted MWCNT caused higher toxicity with lower minimum inhibitory concentration (MIC) (Zardini et al., 2014). To further enhance the anti-microbial property, CNTs can be decorated with metal (Jatoi et al., 2020) or metal oxides nanoparticles or both (Mohammed et al., 2019). Similarly, anti-bacterial activity can be enhanced by grafting amino acids like arginine and lysine (Zardini et al., 2012).

\section{Graphene}

Graphene is a two-dimensional allotrope of carbon that has honeycomb lattice with an atomic bond length of $0.142 \mathrm{~nm}$. Apart from possessing good mechanical, electrical, and thermal property, their high surface area and their effective surface modifications can be used as a drug carrier and also in various tissue engineering fields. Graphene exhibits high anti-bacterial property by damaging the surface of bacteria through its sharp edges, inducing oxidative stress within the bacteria, and stabilizing surface through electrostatic interaction due to wrapping. This property was further enhanced by coating nanoparticles on the surface of graphene (Mohammed et al., 2020).

Several scaffolds prepared using graphene as filler has shown that the presence of graphene has supported and improved the commitment of stem cells towards osteogenic lineage in vitro (Table 3). Presence of graphene activated RhoA/Rho-associated protein kinase that increased the formation of F-actin stress fiber and also for Smad signaling activation for osteogenesis (Xie et al., 2019). Graphene oxide, a derivative of graphene showed toxicity towards MSC abpve $1 \mu \mathrm{g} / \mathrm{ml}$ concentration by generating high intracellular ROS. At low concentration of $0.1 \mu \mathrm{g} / \mathrm{ml}$ graphene

TABLE 3 | Effect of phytochemicals on scaffold towards osteoblasts and microbes.

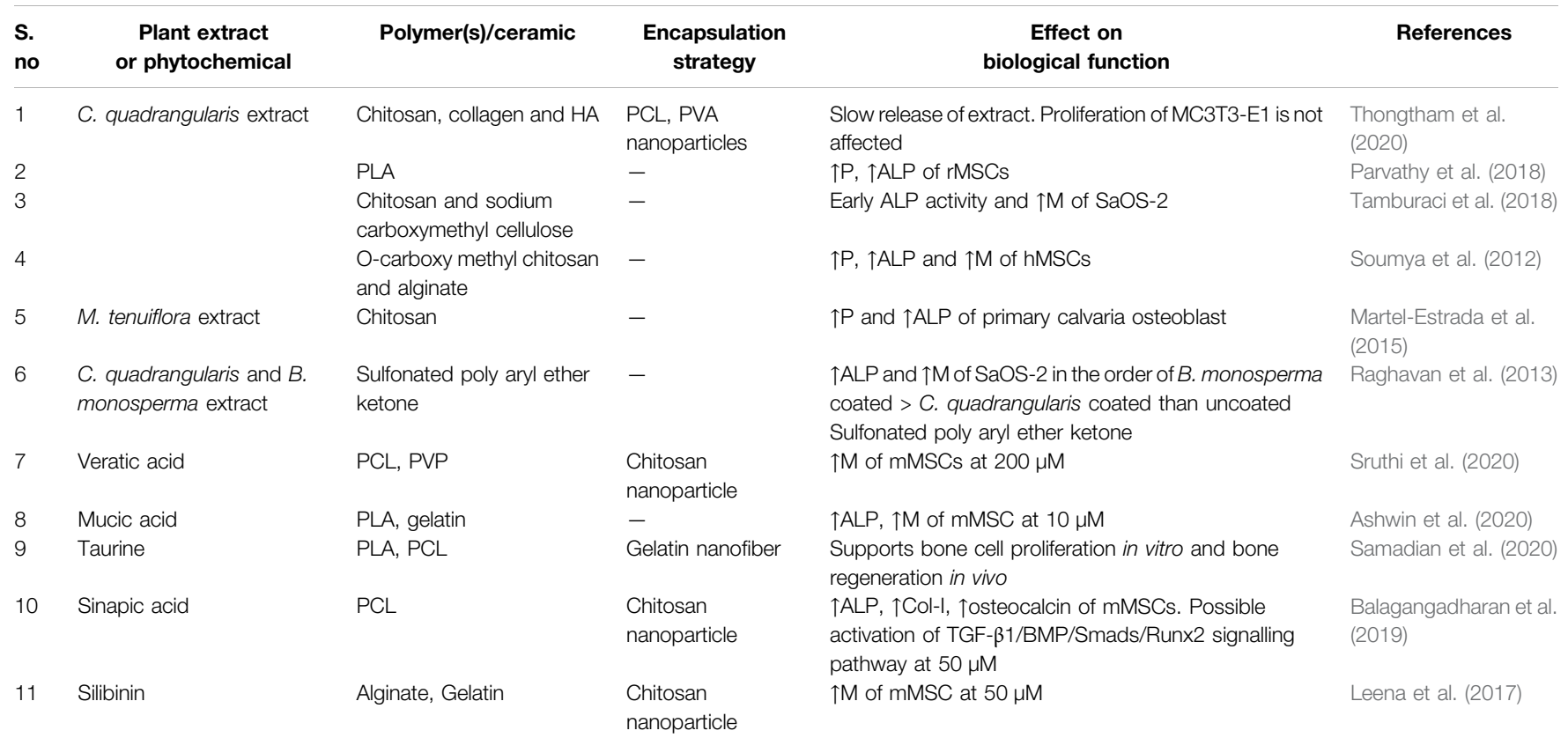


oxide enhanced osteogenesis through NJK and FoxO1 signaling pathway activation (Halim et al., 2019).

Eventhough the carbon based nanofillers prove to posses all the physical cues essential for osteogenic and anti-microbial activity, their major limitation lies in ease of manufacture, their nondegradability property therby carbon nanofillers get accumulated and generate excesses ROS in vivo. The effect of commonly used metal and metal oxide nanoparticles on scaffold towards osteoblasts and microbes function is given in Supplementary Table S3.

\section{Scaffolds With Vitamins}

Ionic balance is essential for active bone remodeling. Also, Vitamins do help in active absorption of ions for bone. Vitamins like A, B complex, C, D, E, and $\mathrm{K}$ are essential for maintaining bone in optimal health (Ahmadiesh and Arabi et al., 2011). Among them, some possess anti-microbial property as well.

Vitamin D is a lipophilic protein responsible for bone formation, resorption, and regeneration. This vitamin helps in the absorption of ions like calcium and phosphorous essential for bone metabolism, absence of which causes osteoporosis in old age. Higher levels can cause calcification along with heart, blood vessels, and kidney damage. Vitamin $\mathrm{D}$ gets activated to calcidiol or calcitriol by UV irradiation of cholesterol in the skin. This vitamin losses it functionality upon exposure to light heat and oxidation. Vitamin D promotes anti-microbial activity by stimulating anti-microbial peptide production of LL-7 and $\beta$-defensin and also induces nitric oxide production (Herscovitch et al., 2014; Fayyazbaksh et al., 2017; Sattary et al., 2019).

Vitamin $\mathrm{E}$ is an anti-oxidant that express anti-inflammatory property. They are usually added into the polymer to render it biocompatible. Initially, it was assumed that vitamin E possess antibacterial activity. Campoccia et al. (2015), observed that the addition of vitamin $\mathrm{E}$ or vitamin $\mathrm{E}$ acetate reduced the adhesion of $S$. aureus and S. epidermidis. Similarly, when vitamin E acetate and vitamin E phosphate, vitamin $\mathrm{E}$ acetate have better anti-adhesive property towards S. epidermis but vitamin E phosphate has better antiadhesive property towards S. epidermis than S. aureus. Vitamin E phosphate has excellent prevention of biofilm towards S. epidermis than S. aureus, than vitamin $\mathrm{E}$ acetate. Vitamin $\mathrm{E}$ acetate and vitamin E phosphate does not have anti-adhesive property and does not prevent the biofilm formation of P. aeruginosa (Bidossi et al., 2017). When vitamin $\mathrm{E}$ phosphate is coated on titanium implant, they stimulated bone deposition even in presence of high bacterial load of $3 \times 10^{4} \mathrm{CFU}$ of S. aureus in the rat model (Lovati et al., 2018).

Vitamin B2 or otherwise called riboflavin is a water-soluble vitamin that usually gets absorbed in the small intestine into blood. Riboflavin supplemented diet can prevent pathogenic infection. Experiments suggested that riboflavin has shown a higher zone of inhibition towards both the Gram strain of bacteria along with C. albicans (Ahgilan et al., 2016). Riboflavin-low density polyethylene composite at $5 \%$ percent loading showed $99.44 \%$ reduction of $E$. coli and $94.31 \%$ reduction of S. aureus (Orusuwan et al., 2019).

Vitamin $C$ is a water-soluble anti-oxidant, that aides in collagen synthesis necessary for bone formation. It also inhibits osteoclasts and various types of cancers including lung, pancreas, oral, cervical, and esophageal. To know the effect of vitamin $\mathrm{C}$ on effective bone formation, ovariectomized rats were subjected to diets with Vitamin C. It was observed that vitamin $\mathrm{C}$ has increased the calcium content in bones, bone mineral density and bone volume fraction. Osteoblast related protein expression like bone morphogenic protein-2 (BMP-2), osteocalcin, collagen-I has increased and reduced osteoclast related protein expression (Choi et al., 2019). Vitamin C also exhibited anti-bacterial property against E. coli and S. aureus (Voss et al., 2018). Some studies show that vitamin $\mathrm{C}$ at a concentration of $0.31 \mathrm{mg} / \mathrm{ml}$ inhibits $P$. aeruginosa and at $0.15 \mathrm{mg} / \mathrm{ml}$ inhibits $S$. aureus growth. Even at near neutral $\mathrm{pH}$, vitamin $\mathrm{C}$ has potent anti-microbial activity against streptococci (Mousavi et al., 2019).

Vitamin $\mathrm{K}$ is lipophilic and has osteoinductive properties, whose dietary intake increases bone mineral density by producing more osteocalcin and other osteoblast specific genes and reduce osteoclastogenesis. Vitamin $\mathrm{K} 5$ has anti-microbial activity. At concentrations of $80,120,140$, and $220 \mathrm{ppm}$ they are bactericidal towards S. aureus, B. subtilis, P. vulgaris, P. fluorescens, and E. coli (Merrifield and Yang, 1965). The reason is lipophilic substances permeabilize the cell membrane of bacteria, damaging the membrane integrity, causing cell lysis and death (Andrade et al., 2017).

Vitamins along with antibiotics showed synergic effect aginst microbes. The presence of vitmins lowered the MIC of antibiotics. One such example is that vitamin B2 with oxytetracyline or linezolid was effective against MRSA (Shahzad et al., 2018). Similarly, vitamin B2 with ciprofloxacin and azithromycin was effective against MRSA by enhancing ROS production but also ensures host cells protection from inflammation damage (Dey and Bishayi, 2016). Even though vitamins had good anti-microbial property, their stability was the drawback. Factors like temperature, moisture, oxygen, light, $\mathrm{pH}$, oxidizing and reducing agent, presence of metallic ions and other compounds, presence of other vitamins and the combinations of above affected their stability or activity (Ottaway, 2010). These factors can be lowered by using an appropriate encapsulation strategy using a polymer, porous nanoparticles or by intercalating between layered nanoparticle.

\section{Scaffolds With Phytochemicals}

Natural compounds obtained from plant based extracts have been used to treat ailments for ages. Some of them possess osteogenic properties and has been documented in Indian and Chinese traditional medicine. For nearly 2 decades, the compounds responsible for osteogenic and anti-microbial activity has been individually identified and the research on this front is incomplete. Some of the phytochemicals or plant based extract that has both osteogenic and anti-microbial activities are discussed in this section.

Shrubs like Cissus quadrangularis possess vitamin C, vitamin A, carotene, and anabolic steroidal substances along with ions like calcium, phosphorus, zinc, iron, sodium, cadmium, copper and magnesium essential for their use in bone tissue engineering. They also possess anti-osteoporosis, anti-bacterial, bone fracture 
healing activity along with free radical scavenging and antioxidant potential. The fresh and dried stem extracts of $C$. quadrangularis showed anti-oxidant activity and it is also observed to have high anti-bacterial activity against Grampositive bacteria like $B$. subtilis, $B$. cereus, $S$. aureus than Gram-negative bacteria like $P$. aeruginosa and $E$. coli but they exhibited significantly higher resistance towards plant extracts (Chidambara Murthy et al., 2003). When patients with maxillofacial fracture were supplemented with $500 \mathrm{mg}$ of $C$. quadrangularis thrice a day for 6 weeks, showed less tissue reaction, early callus formation and complete new bone formation in 7 weeks (Brahmkshatriya et al., 2015). C. quadrangularis diet inhibits bone loss in ovariectomized mice (Banu et al., 2012).

Medicarpin, cajanin, formonentin, isoformonentin, cladrin present in ethanol extract from the bark of Butea monosperma found to possess osteogenic activity (Maurya et al., 2009). Medicarpin treatment generated new bone in ovariectomized and osteopenic mice models by activating Wnt/canonical and notch signaling pathway (Dixit et al., 2015). They have osteoblastogenic, anti-osteoclastogenic activity, and increases bone volume fraction (Tyagi et al., 2010). Also, prevents bone loss in ovariectomized and collagen-induced arthritis models (Mansoori et al., 2020). Medicarpin also possesses anti-fungal activity towards Cladosporium cladosporioides (Bandara et al., 1989). They usually get distributed in the liver, bone marrow, small intestine, lungs, and kidney and gets excreted from the body via urine (Taneja et al., 2020).

Dalbergia sissoo also known as Indian Rosewood, whose leaves extract was rich in phytoestrogens, which exhibits bone forming property. Phytoestrogens are naturally occurring, chemically similar to $17 \beta$-estradiol, which are metabolized and can be eliminated from the body. Phytoestrogens possess osteoprotective and fracture healing properties (Khedgikar et al., 2017). It restores bone mineral density, bone volume fraction, and mineralization by enhancing osteoblast and reducing osteoclast activity in ovariectomized rats (Karvande et al., 2017). Ethanolic extract from bark showed higher antibacterial activity towards $S$. aureus, M. leteus and E. aerogenes than leaves. Both bark and leaf extract showed little anti-fungal activity against $A$. niger, A. alternate, and S. commune (Majeed et al., 2019). Dalbergia sissoo also possesses polyphenolic compounds that belong to a class of neoflavonoids, exhibited anti-oxidant and anti-inflammatory properties. Dalbergin is a neoflavinoid enhanced ALP activity, mineralization, enhanced bone volume fraction, osteoblast, and reduced osteoclast expression in ovariectomized rats (Choudhary et al., 2016). Dalbergia sissoo based magnesium oxide particle showed good anti-bacterial activity against $E$. coli and $R$. solanacearum (Khan et al., 2020).

Ethanolic extracts from the flower of Pterospermum acerifolium contains 17 compounds. Among them, pterospermin A (4'-(2-methoxy-4-(1,2,3-trihydroxypropyl)) phenoxy luteolin), pterospermin $\mathrm{C}$ (3,5-dihydroxyfuran-2(5H)one) and trans-triliroside showed higher ALP activity, mineralization and osteoblastic gene expression in the concentration range of 10-100 pM (Dixit et al., 2011).
Similarly, seed coats of Pterospermum acerifolium contains two phytoceramides (A and B), two acylated phytosterol (A and B), and five other compounds. Among them, the two phytoceramides at $1 \mathrm{nM}$ concentration, increased ALP activity, mineralization, and osteoblastic gene expression. When neonatal pups of 1-2 days old were treated with phytoceramides $A$ and $B$ at $10 \mathrm{mg} / \mathrm{kg}$ showed higher expressions of osteoblast (Dixit et al., 2012). Extracts from the bark of Pterospermum acerifolium showed promising antibacterial activity against $B$. lichenoformis, S. aureus, P. florescence and S. typhimurium (Panda and Dutta, 2011).

Extract from fruits of Cupressus sempervirens contains sugiol, trans-communic acid, 15-acetoxy imbricatolic acid and imbricatolic acid had effects on calvarial derived osteoblast cells. Among them, sugiol has good mineralization potential and expressed high osteogenic markers like BMP-2. On ovariectomized rat, dietary intake of $1 \mathrm{mg} / \mathrm{kg}$ of rat exhibited osteoprotective property and also improved biomechanical properties of the bone (Khan et al., 2014). The methanol extract of Cupressus sempervirens showed anti-bacterial activity against E. faecalis, S. aureus, K. pneumonia, and P. aeruginosa (Selim et al., 2014).

Ethanol extract of Peperomia pellucida is found to have fracture healing property. When rats with drill-hole femur injury surgery were orally administered with $200 \mathrm{mg} / \mathrm{kg}$ showed higher calcein content and bone volume fraction. In vitro study with BMSC also confirms high mineralization and osteoblastic gene expression (Ngueguim et al., 2013). Mineral content in aqueous extract contains potassium, phosphorous, magnesium, calcium, and sodium. Administration of aqueous extract increased calcium level and ALP in serum and bone, concluding that it has dose-dependent fracture healing property (Florence et al., 2017). Essential oil and extract from leaves, stem, flowers, and even the whole plant has anti-bacterial and antifungal properties (Alves et al., 2019).

Ulmus wallichiana also known as Himalayan elm is used to heal bone fractures in Indian traditional medicine. The bark of Ulmus wallichiana contains a flavanol called (2S,3S)Aromadendrin-6-C- $\beta$-D-glucopyranoside that stimulates osteoblast expression, maturation and also during estrogen deficiency. It also inhibits bone marrow cells towards osteoclast differentiation giving them an osteoprotective property. It also inhibits adipogenic differentiation and induces apoptosis and does not evoke undesirable effects in the uterus (Swarnkar et al., 2011). Similarly, compounds like quercetin-6-C- $\beta$-D-glucopyranoside, ulmoside A, and B were also found to have an osteogenic property (Rawat et al., 2009). Also, naringenin-6-Cglucoside increased ALP activity and osteogenic gene expression and maintains bone volume fraction in ovariectomized mice (Swarnkar et al., 2012). Ethyl acetate extract from the bark of Ulmus wallichiana has a better antioxidant property and showed greater anti-bacterial activity against E. coli, B. subtilis, S. aureus, P. aeruginosa and antifungal activity against $A$. fumigates and $A$. flavus than chloroform extract (Bora et al., 2018).

Tinospora cordifolia in ayurvedic medicine is considered as "nectar of immortality" because of various property it possesses. 
Ethanolic extract of Tinospora cordifolia increased ALP activity, mineralization in both MG3 and osteoblasts, and also acts as an osteoprotective agent (Abiramasundari et al., 2012). They possess anti-oxidant activity (Saha and Ghosh, 2012) and also different extracts of this species possess anti-microbial activity against $S$. epidermidis, E. faecalis, S. aureus, P. aeruginosa, K. pneumonia, E. coli, P. mirabilis, S. marcescens, C. freundii, C. koseri and E. cloacae (Narayanan et al., 2011).

Achyranthes bidentata is used in one of the herb formula in Chinese medicine for bone and mineral metabolism. Butanolic extract from the root (He et al., 2010), alkaline crude polysaccharide ABPRB (Zhang et al., 2018a; Zhang et al., 2018b), AB70 water soluble polysaccharide (Zhang et al., 2019) in ovariectomized rat, fructan ABW50-1 (Yan et al., 2019) and polysaccharide ABPB-2 (Zhang et al., 2018a; Zhang et al., 2018b) in zebrafish model of glucocorticoid induced osteoporosis, induced osteoprotective effect. Oral dosage of $500 \mathrm{mg} / \mathrm{kg} /$ day for 16 week in ovariectomized- osteoporosis induced rats maintained bone volume fraction and bone mineral density (Zhang et al., 2012). Fructan ABW70-1 increased proliferation, ALP activity, mineralization and osteogenic gene expression in MC3T3-E1 (Zhang et al., 2019).

Scutellarian 7-O- $\beta$-D-glucopyranoside present in butanol fraction of Kigelia pinnata between the concentration range of $10 \mathrm{nM}$ and $1 \mu \mathrm{M}$ showed higher ALP activity and mineralization in calvarial osteoblast (Ramakrishna et al., 2017). The methanol extract of leaves and bark extract of Kigelia pinnata exhibited good anti-bacterial activity against $S$. aureus, B. suubtilis, E. coli and $P$. aeruginosa and anti-fungal activity against $C$. albicans (Agyare et al., 2013).

Withania somnifera also known as Ashwagandha in Ayurveda has multi-therapeutic purposes. The powder of root contains phytosterols, polyphenols, flavonoids, and vitamin C that have anti-arthritic properties (Rasool and Varalakshmi, 2007). Ethanolic root extract possesses anti-osteoporotic activity (Nagareddy and Lakshmana, 2006). Withaferin A present in leaves of Withania somnifera is known to reduce osteoclastogenic expression and promotes bone regeneration in ovariectomized mice (Khedgikar et al., 2013; Khedgikar et al., 2015). Water and chloroform extract from the unripened and ripened fruit of Withania somnifera possess anti-bacterial activity against $P$. aeruginosa (Singariya et al., 2012) and methanolic leaf extract inhibits MRSA (Bisht and Rawat, 2014).

Curcumin, a phenolic compound obtained from Curcum longa is nown for its bone healing properties according to Indian traditional medicine. They also exhibit anti-oxidant, anti-inflammatory (Zambrano et al., 2018), anti-tumorigenic and anti-microbbial properties. The synergistic effect of curcumin along with antibiotics like oxacillin, ampicillin, ciprofloxacin, norfloxacin and erythromycin reduced the MIC of antibiotics aginst MRSA (Zhou et al., 2017).

Epigallocatechin-3-gallate, a polyphenolic compounds from dried tea leaves has anti-tumor, anti-oxidation and antimicrobial properties. This polyphenolic compound have been studied in vitro towards dental adhesive, barrier membrane, bone substitute material, anti-caries applications. They inhibit bacterial colonization, improves cell viability, compatibility, osteogenic activity, and reduces ROS production (Liao et al., 2020).
The listed phytochemicals in this sections are not the only phytochemicals that has both osteogenic (Suvarna et al., 2018) and anti-microbial property. The research in the usage of phytochemicals are still in vitro. The in vivo effect of phytochemicals and the mechanism that makes them osteogenic, the maximum dosage and their release kinetics is still needed to be evaluated. Along with this, the overall cost of phytochemicals, the shelf life of phytochemicals based scaffold should be further evaluated.

\section{Polymer Scaffolds With Anti-Microbial Peptide}

To tackle narrow spectrum of antimicrobial agent and microbial resistance, new class of molecules called anti-micobial peptide (AMP), derived from immune responses of multicellular organisms is gaining attention. Many recent studies have been focused on incorporating AMPs into scaffold for othopedic application to make them anti-microbial. AMPs are cationic amphiphilic molecule with 10-50 amino acid residues on their structure. AMPs disrupt microbial membrane by inserting their hydrophobic residue through the lipid bilayer and some AMPs inhibit nucleic acid, protein or cell wall synthesis. The limitations of AMPs are their in vivo stability, susceptible to inactivation and undesired cytotoxicity. These limitations can be overcome by using nanoparticles as the drug delivery system for AMPs (Makowski et al., 2019), by grafting or immobilizing AMP on the surface or by attaching non-natural polyglycine (Hasan et al., 2020a; Hasan et al., 2020b; Castelletto et al., 2020) to offer protease resistance and enhanced lipid membrane permeability. Many studies redarding surface grafting on titanium surface is reported in the literature. When AMP of polyphemusin I was grafted with diphosphoserine, they inhibited dental plaque biofilm caused by $S$. mutans because the modifications caused tooth binding ability without affecting the cytocompatibility (Zhang et al., 2019). Similarly, when cationic peptide LL37 binded with HA to make PCL/HA composite, LL37's cytotoxicity was circumvented along with retaining bactericidal acitivity against $S$. mutans (Fateme et al., 2019). Also, LL37 was found to promote odonto/osteogenic differentiation of apical papilla stem cells (Cheng et al., 2020). When AMP of ponericin G1 and BMP-2 is encapsulated by polydopamine and coated on PLGA, along with osteogenic differentiation and mineralization of MCT3-E1, the scaffold exhibited anti-bacterial activity against $E$. coli and S. aureus (Chen et al., 2019).

\section{Polymer Scaffolds and Its Chemical Modifications}

To design an anti-microbial resorbable scaffold, either the polymer base should possess anti-microbial property or the scaffold should have anti-microbial nanofiller or extracts within or chemical grafting antibiotics on its surface. Surface grafting of antibiotics, antimicrobial polymer or addition of phytochemical extract on the scaffold has limited shelf life. Therefore there is a need for polymers that has either innate anti-microbial property or their chemical modification renders the polymer its permanent anti- 
microbial property and also to reduce the need for anti-microbial nanofiller or extracts or antibiotics.

Chitosan is a deacetylated form of chitin usually derived from the exoskeleton of crustaceans has innate anti-microbial property. They get dissolved only at slightly acidic condition and their surface charge becomes positive in acidic medium but not at neutral $\mathrm{pH}$. Amine group, secondary hydroxyl and primary hydroxyl group in C-2, C-3 and C-6 position are nucleophilic functional groups in chitosan. Therefore, various modifications can be done to incorporate permanent positive charge at neutral $\mathrm{pH}$ and enhancing solubility in the aqueous medium. Addition of alkyl, aromatic, carboxyalkyl, quaternary ammonium groups, amino acids, and peptides into chitosan are the various forms to increase its anti-microbial potential. Four models are proposed for their anti-bacterial mechanisms, 1) electrostatic interaction between positively charged chitosan derivative with negatively charged peptidoglycan causing them to hydrolyze, 2) change in permeability of outer membrane because of ionic interaction leading to restriction in nutrient transport and osmotic pressure buildup, 3) perforating cell wall and interacting with DNA by preventing its transcription and disturbing protein and mRNA synthesis and 4) higher chelating ability with metal ions and hindering with microbes overall growth (Sahariah and Masson, 2017).

Cellulose being a highly renewable biopolymer does not possess inherent anti-microbial property. Imparting positive charge on the backbone of cellulose can be done through quaternary ammonium moiety, aminoalkyl, or aminosioane, quaternized halamine incorporation. Quaternary ammonium moiety interacts with cell membrane through electrostatic interaction. They bind to cell membrane, compromise their permeability leading to bacterial apoptosis. Aminoalkyl functionalization on cellulose not only imparts polycationic nature but also lipophilic. Its lipophilicity increased with increased chain length which helped the functional groups to penetrate into cell membrane, therefore, further enhancing its anti-bacterial effect. Quaternized halamine incorporation into cellulose releases halogens, thereby, inactivating bacterial cells of their growth (Tavakolian et al., 2020).

Biopolymers like silk has attracted researchers in orthopedics for their mechanical property and good processibility. They are biocompatible and their slow degradation helpful in repairing critical size defects. Silk provides a better surface for cell adhesion and mineralization (Bhattacharjee et al., 2017). Anti-bacterial property of silk has conflicting results. Cocoon components before and after proessing dinot resist E. coli growth. The presence of processing chemicals may inhibit or kill bacteria (Kaur et al., 2014). Silk spun by genetically modified silkworm has inherent antibacterial activity against $E$. coli (Saviane et al., 2018).

PCL is one of the extensively studied polymer in tissue engineering. Even though their performance is excellent in vivo, they lack anti-microbial property. This lacuna is usually overcome by adding metal, metal oxides or carbon based filler. A recent study on grafting poly (Z-Lysine) with PCL showed antibacterial activity. The positively charged lysine get attracted to the negatively charged cell membrane. PCL being hydrophobic gets inserted into the cell membrane causing them to rupture and leak the bacteria's intracellular contents. The balance between cationic charge and hydrophilic chain is the key for effective bactericide (Zhou et al., 2019).

Citrate based polymers do possess anti-microbial activity. Citric acid in the polymer lowers $\mathrm{pH}$ in the cell, chelates with metal ion and causes damage to proteins, DNA and cell membranes. Poly(octamethylene citrate) and poly(octamethylene maleate anhydride citate) has good anti-bacterial activity against E. coli and S. aureus (Su et al., 2014). Polycitrate and silica polycitrate also showed anti-bacterial activity against $S$. aureus (Du et al., 2015). When poly(octanediol-citrate) crosslinked with poly- $\varepsilon$-lysine, they showed excellent anti-bacterial activity against $E$. coli, $S$. aureus, $P$. aeruginosa and E. faecalis (Li et al., 2018).

Similarly, chemical modifications are made to the naturally available gums that have weak anti-microbial property. Polyanionic polysaccharides like chichi gum from Sterculia striata upon acetylation have shown to have higher inhibitory effect against C. albicans, E. coli, P. aeruginosa, S. typhimurium and K. pneumonia (Braz et al., 2020). Anionic heteropolysaccharide like cashew gum from Anacardium occidentale, with increasing quaternization degree showed higher anti-staphylococcal activity (Quelemes et al., 2017). Non-ionic Guar gum when crosslinked with polyacrylic acid strongly inhibits E. coli and S. aureus (Kaith et al., 2015).

\section{TESTING SCAFFOLDS FOR ANTI-MICROBIAL PROPERTY}

Anti-bacterial activity of scaffolds can be analyzed in vitro using disc diffusion assay and dynamic contact assay. In disc diffusion assay, the bacterial suspension is evenly spread across the agar plate, followed by placing a sterilized scaffold in the middle and then incubated at $37^{\circ} \mathrm{C}$ for a particular duration, and then the diameter of inhibition zone is noted. In dynamic contact assay, the scaffold is dipped and incubated in the bacterial suspension. Then the serially diluted bacterial solution was spread on a nutrient agar plate and cultured at $37^{\circ} \mathrm{C}$ and CFUs can be counted (Bai et al., 2020). Similarly, in vitro adhesion studies of bacteria or bacteria and host cells (osteoblasts and/or macrophages) co-culture incubated at $37^{\circ} \mathrm{C}$ for a specific period, to analyze the bacteria and cell's attachment and proliferative ability on surface through live/dead staining (Mehrjou et al., 2019). To analyse bacteria colonization and biofilm formation on various subtrates and antimicrobials efficacy, microtiter plate based model (Nett et al., 2011) can be used to mimick in vivo ativity. Microtiter plate based model is one of the cheap but labour intensive study that can be used to analyse biofilm mass and their metabolic activity under the influence of antimicrobial agents (Vandecandelaere et al., 2016). To simulate in vivo environment, $3 \mathrm{D}$ in vitro models are created to effectively reproduce the bacteria and host interaction in osteomyelitis (Hofstee et al., 2020).

For chronic osteomyelitis animal model, the Nordon method was employed. Hole is drilled into the medullary cavity of rabbit's right tibia and $0.1 \mathrm{ml}$ of $3 \times 10^{7} \mathrm{CFU} / \mathrm{ml}$ of $S$. aureus suspension in nutrient media is injected and sealed using bone wax for 4 weeks. Then rabbits were treated with debridement and the scaffold is inserted. After 
implantation at specific time points, general observations, X-ray imaging, gross pathology, Micro CT evaluation, and histological evaluation can be conducted (Wang et al., 2017).

\section{CONCLUSION AND FUTURE SCOPE}

This review discussed various nanoparticles be it ceramic, metal or carbon based along with polymers and its chemical modification that were used in scaffolds to improve their antimicrobial and osteogenic activity. These nanoparticles are extensively studied over years both in vitro and in vivo. The extent of substitution of metal ion(s) into the ceramic changed the crystal structure and its solubility. Also, in the case of scaffold with metal and metal oxides and carbon based nanofiller, the release kinetics was determined by the degradation of the polymer, size and concentration of nanoparticle that had a potential impact in the scaffolds anti-microbial and osteogenic property. These nanoparticles, have wide range of applications from bio-imaging, tissue regeneration, drug delivery, and so on. Due to their small size, large surface to volume ratio, surface charge, and reactivity, they produce ROS, act as nanoknives, and their surface charge either repel away microbes or destabilize their cell membrane. But they get distributed to all the organs, present in vivo for long term, and mainly produce massive ROS which becomes cytotoxic till they are degraded by macrophages in vivo (Yang and Zhang, 2019).

Biomolecules like vitamins, even though they possess dual properties like anti-microbial and osteogenic activity in vitro, their in vivo release kinetics and efficacy have to be further explored. Similarly, AMPs have good antimicrobial property but their cytotoxicity can be overcome by modulating their release kinetics by using suitable scaffold design. Their drawbacks are their storage conditions, stability, and shelf life are a major concern.

Phytochemical extract is a cocktail of various vitamins, metal ions, and phytochemicals. Their performance in vivo shows an excellent osteogenic property. But very few phytochemical extracts were translated into scaffolds. Therefore, there is a need to elucidate the osteogenic potential of different components in the extract. Many traditional Indian plants are used in households of Indian family for their positive effect in bones. But extensive scientific studies do lack in that front. There is a need to gather information about various plants and their phytochemicals from different native traditions and their potential use in bone tissue engineering. Drawbacks are difficulty in extraction, separation, purification, and their large scale production.

Polymers are the base of a degradable scaffold. Except for chitosan, many polymers requires either chemical modification or addition of bioactive fillers to impart anti-microbial property. Currently, it is encouraging to observe the research being focused on developing and modifying already existing polymers to possess anti-microbial properties. But ease of synthesis and reproducibility is one of the concerns in this front. Inspiration from naturally occurring monomers like citric acid, maleic acid and tartaric acid are used in polymer synthesis with antimicrobial property.
While manufacturing and implanting scaffold in vivo, it's important to maintain chemical homogeneity of the scaffold and also to map the spatial-temporal interaction between scaffold and various cellular activites by it, on it and around it. Various state of art characterization tools can be employed to study the biological ultrastucture (using volume electron microscopy and super resolution optical microscopy) and biochemical composition of extra cellular matrix (using Raman spectroscopic mapping, fluorescene imaging and mass spectroscopic imaging). Similarly one can also employ micro-computed tomography to track the bone formation in an osteomyelitis model. Also, machine language tools can be incorporated while studing the images of differrent phases of scaffold interaction with host and bacteria cells and the information between different individuals and be processed to give a predictive model that can be employed to trobleshoot a similar orthopaedic complications in future (Armstrong and Stevens, 2019; Kim et al., 2019).

All the advantages that were discussed above are suitable to minimize microbial adhesion and kill them on contact on the scaffold. But the dead microbes shield the incoming microbes from scaffold's anti-microbial property and provide them a suitable site for biofilm growth (Goodwin et al., 2016). Therefore, the nonofiller incorporated inside scaffold upon degradation, should be able to penetrate inside biofilm and destabilize them [Example $\mathrm{ZnO}$ (Mahamuni-Badiger et al., 2020) and Carbon dot (Ran et al., 2019)]. Also, the nanoparticle should be provided with an additional functional group by attaching biomolecules (Turcheniuk et al., 2015) or antibiotics on their surface to enhance their properties against biofilm elimination and reduce microbial mutation against nanoparticle (Shkodenko et al., 2020).

In spite of the presence of various options to eliminate microbes and support osteogenesis in vitro, the in vivo efficacy for a longer term needs to be evaluated. To reduce the antibiotic toxicity and effective osteomyelitis treatment, a cocktail of iron oxide, $\mathrm{CNT}$ and gentamicin was used in bacterial capturing and effective microwave assisted bacterial killing of E. coli and MRSA (Qiao et al., 2020). Similarly, studies that involves a cocktail of nanofillers with biomolecules on scaffold have to be designed to not only treat osteomyelitis but also support osteogenesis and their long term in vivo efficacy can be viewed as on opportunity that can open newer avenues for an all in one patient specific scaffold that is lacking in the market for the bone graft.

\section{AUTHOR CONTRIBUTIONS}

AP Literature review and manuscript writing. JB Literature review, manuscript writing, and evaluation.

\section{SUPPLEMENTARY MATERIAL}

The Supplementary Material for this article can be found online at: https://www.frontiersin.org/articles/10.3389/fmats.2020.594686/ full\#supplementary-material. 


\section{REFERENCES}

Abbaszadegan, A., Ghahramani, Y., Gholami, A., Hemmateenejad, B., Dorostkar, S., Nabavizadeh, M., et al. (2015). The effect of charge at the surface of silver nanoparticles on antimicrobial activity against Gram-positive and Gramnegative bacteria: a preliminary study. J. Nanomater. 72, 654. doi:10.1155/ 2015/720654

Abiramasundari, G., Sumalatha, K. R., and Sreepriya, M. (2012). Effects of Tinospora cordifolia (Menispermaceae) on the proliferation, osteogenic differentiation and mineralization of osteoblast model systems in vitro. J. Ethnopharmacol. 141 (1), 474-480. doi:10.1016/j.jep.2012.03.015

Abutalib, M. M., and Yahia, I. S. (2017). Novel and facile microwave-assisted synthesis of Mo-doped hydroxyapatite nanorods: characterization, gamma absorption coefficient, and bioactivity. Mater. Sci. Eng. C. 78, 1093-1100. doi:10.1016/j.msec.2017.04.131

Agyare, C., Dwobeng, A. S., Agyepong, N., Boakye, Y. D., Mensah, K. B., Ayande, P. G., et al. (2013). Antimicrobial, antioxidant, and wound healing properties of Kigelia africana (Lam.) Beneth. and Strophanthus hispidus DC. Adv. Pharmacol. Sci. 69, 2613. doi:10.1155/2013/692613

Ahgilan, A., Sabaratnam, V., and Periasamy, V. (2016). Antimicrobial properties of vitamin B2. Int. J. Food Prop. 19 (5), 1173-1181. doi:10. 1016/j.sjbs.2015.09.004

Ahmadieh, H., and Arabi, A. (2011). Vitamins and bone health: beyond calcium and vitamin D. Nutr. Rev. 69 (10), 584-598. doi:10.1111/j.1753-4887.2011. 00372.x

Ai, F., Chen, L., Yan, J., Yang, K., Li, S., Duan, H., et al. (2020). Hydroxyapatite scaffolds containing copper for bone tissue engineering. J. Sol. Gel Sci. Technol. 1-12. doi:10.1007/s10971-020-05285-0

Alam, H. A., Dalgic, A. D., Tezcaner, A., Ozen, C., and Keskin, D. (2019). A comparative study of monoaxial and coaxial PCL/gelatin/Poloxamer 188 scaffolds for bone tissue engineering. Int. J. Polym. Mater. Polym. Biomater. 15, 811. doi:10.1080/00914037.2019.1581198

Alves, N. S. F., Setzer, W. N., and da Silva, J. K. R. (2019). The chemistry and biological activities of Peperomia pellucida (Piperaceae): a critical review. J. Ethnopharmacol. 232, 90-102. doi:10.1016/j.jep.2018.12.021

Andrade, J. C., Braga, M. F. B. M., Guedes, G. M. M., Tintino, S. R., Freitas, M. A., Quintans, L. J., Jr, et al. (2017). Menadione (vitamin K) enhances the antibiotic activity of drugs by cell membrane permeabilization mechanism. Saudi J. Biol. Sci. 24 (1), 59-64. doi:10.1016/j.sjbs.2015.09.004

Arciola, C. R., Campoccia, D., and Montanaro, L. (2018). Implant infections: adhesion, biofilm formation and immune evasion. Nat. Rev. Microbiol. 16 (7), 397. doi:10.1038/s41579-018-0019-y

Armstrong, J. P., and Stevens, M. M. (2019). Emerging technologies for tissue engineering: from gene editing to personalized medicine. Tissue Eng. 25 (9-10), 688-692. doi:10.1089/ten.TEA.2019.0026oi:

Ashwin, B., Abinaya, B., Prasith, T. P., Chandran, S. V., Yadav, L. R., Vairamani, M., et al. (2020). 3D-poly (lactic acid) scaffolds coated with gelatin and mucic acid for bone tissue engineering. Int. J. Biol. Macromol. 162, 523-532. doi:10. 1016/j.ijbiomac.2020.06.157

Azeena, S., Subhapradha, N., Selvamurugan, N., Narayan, S., Srinivasan, N., Murugesan, R., et al. (2017). Antibacterial activity of agricultural waste derived wollastonite doped with copper for bone tissue engineering. Mater. Sci. Eng. C. 71, 1156-1165. doi:10.1016/j.msec.2016.11.118

Azevedo, H. S., Reis, R. L., and Gama, N. A. (2005). Understanding the enzymatic degradation of biodegradable polymers and strategies to control their degradation rate.

Bai, J., Wang, H., Gao, W., Liang, F., Wang, Z., Zhou, Y., et al. (2020). Melt electrohydrodynamic $3 \mathrm{D}$ printed poly ( $\varepsilon$-caprolactone)/polyethylene glycol/ roxithromycin scaffold as a potential anti-infective implant in bone repair. Int. J. Pharm. 576, 118941. doi:10.1016/j.ijpharm.2019.118941

Bakhsheshi-Rad, H. R., Hamzah, E., Abbasizadeh, N., Najafinezhad, A., and Kashefian, M. (2018). Synthesis of novel nanostructured bredigite-amoxicillin scaffolds for bone defect treatment: cytocompatibility and antibacterial activity. J. Sol. Gel Sci. Technol. 86 (1), 83-93. doi:10.1007/ s10971-018-4606-1

Balagangadharan, K., Trivedi, R., Vairamani, M., and Selvamurugan, N. (2019). Sinapic acid-loaded chitosan nanoparticles in polycaprolactone electrospun fibers for bone regeneration in vitro and in vivo. Carbohydr. Polym. 216, 1-16. doi:10.1016/j.carbpol.2019.04.002

Bandara, B. R., Kumar, N. S., and Samaranayake, K. S. (1989). An antifungal constituent from the stem bark of Butea monosperma. J. Ethnopharmacol. 25 (1), 73-75. doi:10.1016/0378-8741(89)90046-9

Banu, J., Varela, E., Bahadur, A. N., Soomro, R., Kazi, N., and Fernandes, G. (2012). Inhibition of bone loss by Cissus quadrangularis in mice: a preliminary report. J. Osteoporos. 10, 206. doi:10.1155/2012/101206

Baptista, P. V., McCusker, M. P., Carvalho, A., Ferreira, D. A., Mohan, N. M., Martins, M., et al. (2018). Nano-strategies to fight multidrug resistant bacteria-“A Battle of the Titans". Front. Microbiol. 9, 1441. doi:10.3389/ fmicb.2018.01441

Begam, H., Kundu, B., Chanda, A., and Nandi, S. K. (2017). MG63 osteoblast cell response on $\mathrm{Zn}$ doped hydroxyapatite (HAp) with various surface features. Ceram. Int. 43 (4), 3752-3760. doi:10.1016/j.ceramint.2016.12.010

Belgheisi, G., Nazarpak, M. H., and Hashjin, M. S. (2020). Bone tissue engineering electrospun scaffolds based on layered double hydroxides with the ability to release vitamin D3: fabrication, characterization and in vitro study. Appl. Clay Sci. 185, 105434. doi:10.1016/j.clay.2019.105434

Beyene, Z., and Ghosh, R. (2019). Effect of zinc oxide addition on antimicrobial and antibiofilm activity of hydroxyapatite: a potential nanocomposite for biomedical applications. Mater. Today Commun. 21, 100612. doi:10.1016/j. mtcomm.2019.100612

Bhadra, C. M., Truong, V. K., Pham, V. T., Al Kobaisi, M., Seniutinas, G., Wang, J. Y., et al. (2015). Antibacterial titanium nano-patterned arrays inspired by dragonfly wings. Sci. Rep. 5 (1), 1-12. doi:10.1038/srep6817

Bhattacharjee, P., Kundu, B., Naskar, D., Kim, H. W., Maiti, T. K., Bhattacharya, D., et al. (2017). Silk scaffolds in bone tissue engineering: an overview. Acta Biomater. 63, 1-17. doi:10.1016/j.actbio.2017.09.027

Bhattacharya, R., Kundu, B., Nandi, S. K., and Basu, D. (2013). Systematic approach to treat chronic osteomyelitis through localized drug delivery system: bench to bed side. Mater. Sci. Eng. C. 33 (7), 3986-3993. doi:10. 1016/j.msec.2013.05.036

Bidossi, A., Bortolin, M., Toscano, M., De Vecchi, E., Romanò, C. L., Mattina, R., et al. (2017). In vitro comparison between $\alpha$-tocopheryl acetate and a-tocopheryl phosphate against bacteria responsible of prosthetic and joint infections. PloS One 12 (7), e0182323. doi:10.1371/journal.pone.0182323

Birt, M. C., Anderson, D. W., Toby, E. B., and Wang, J. (2017). Osteomyelitis: recent advances in pathophysiology and therapeutic strategies. J. Orthop. 14 (1), 45-52. doi:10.1016/j.jor.2016.10.004

Bisht, P., and Rawat, V. (2014). Antibacterial activity of Withania somnifera against Gram-positive isolates from pus samples. Ayu. 35 (3), 330. doi:10.4103/ 0974-8520.153757

Bora, K. S., Kumar, A., and Bisht, G. (2018). Evaluation of antimicrobial potential of successive extracts of Ulmus wallichiana Planch. J. Ayurveda Integr. Med. 9 (3), 190-194. doi:10.1016/j.jaim.2017.02.009

Bose, S., Sarkar, N., and Vahabzadeh, S. (2019). Sustained release of vitamin C from PCL coated TCP induces proliferation and differentiation of osteoblast cells and suppresses osteosarcoma cell growth. Mater. Sci. Eng. C. 105, 110096. doi:10. 1016/j.msec.2019.110096

Brahmkshatriya, H. R., Shah, K. A., Ananthkumar, G. B., and Brahmkshatriya, M. H. (2015). Clinical evaluation of Cissus quadrangularis as osteogenic agent in maxillofacial fracture: a pilot study. AYU. 36 (2), 169. doi:10.4103/0974-8520. 175542

Braz, E. M. A., Silva, S. C. C. C., Brito, C. A. R. S., Carvalho, F. A. A., Alves, M. M. M., Barreto, H. M., et al. (2020). Modified chicha gum by acetylation for antimicrobial and antiparasitic applications: characterization and biological properties. Int. J. Biol. Macromol. 29, 524. doi:10.1016/j.ijbiomac.2020. 05.219

Campoccia, D., Visai, L., Renò, F., Cangini, I., Rizzi, M., Poggi, A., et al. (2015). Bacterial adhesion to poly-(d,l) lactic acid blended with vitamin E: toward gentle anti-infective biomaterials. J. Biomed. Mater. Res. 103 (4), 1447-1458. doi:10.1002/jbm.a.35284

Cao, W., Wang, X., Li, Q., Peng, X., Wang, L., Li, P., et al. (2018). Designing of membrane-active nano-antimicrobials based on cationic copolymer functionalized nanodiamond: influence of hydrophilic segment on antimicrobial activity and selectivity. Mater. Sci. Eng. C. 92, 307-316. doi:10. 1016/j.msec.2018.06.067 
Castelletto, V., Seitsonen, J., Tewari, K. M., Hasan, A., Edkins, R. M., Ruokolainen, J., et al. (2020). Self-assembly of minimal peptoid sequences. ACS Macro Lett. 9 (4), 494-499. doi:10.1021/acsmacrolett.9b01010

Castiglioni, S., Cazzaniga, A., Albisetti, W., and Maier, J. A. (2013). Magnesium and osteoporosis: current state of knowledge and future research directions. Nutrients 5 (8), 3022-3033. doi:10.3390/nu5083022

Chen, J., Zhang, X., Cai, H., Chen, Z., Wang, T., Jia, L., et al. (2016a). Osteogenic activity and antibacterial effect of zinc oxide/carboxylated graphene oxide nanocomposites: preparation and in vitro evaluation. Colloids Surf. B Biointerfaces 147, 397-407. doi:10.1016/j.colsurfb.2016.08.023

Chen, L., Shao, L., Wang, F., Huang, Y., and Gao, F. (2019). Enhancement in sustained release of antimicrobial peptide and BMP-2 from degradable three dimensional-printed PLGA scaffold for bone regeneration. RSC Adv. 9 (19), 10494-10507. doi:10.1039/C8RA08788A

Chen, Z., Bachhuka, A., Wei, F., Wang, X., Liu, G., Vasilev, K., et al. (2017). Nanotopography-based strategy for the precise manipulation of osteoimmunomodulation in bone regeneration. Nanoscale 9 (46), 18129-18152. doi:10.1039/c7nr05913b

Chen, Z., Klein, T., Murray, R. Z., Crawford, R., Chang, J., Wu, C., et al. (2016b). Osteoimmunomodulation for the development of advanced bone biomaterials. Mater. Today 19 (6), 304-321. doi:10.1016/j.mattod.2015.11.004

Cheng, Q., Zeng, K., Kang, Q., Qian, W., Zhang, W., Gan, Q., et al. (2020). The antimicrobial peptide LL-37 promotes migration and odonto/osteogenic differentiation of stem cells from the apical papilla through the Akt/Wnt/ $\beta$-catenin signaling pathway. J. Endod. 13, 8963. doi:10.1016/j.joen.2020. 03.013

Cheng, T., Qu, H., Zhang, G., and Zhang, X. (2018). Osteogenic and antibacterial properties of vancomycin-laden mesoporous bioglass/PLGA composite scaffolds for bone regeneration in infected bone defects. Artif. Cells Nanomed. Biotechnol. 46 (8), 1935-1947. doi:10.1080/21691401.2017.1396997

Chidambara Murthy, K. N., Vanitha, A., Mahadeva Swamy, M., and Ravishankar, G. A. (2003). Antioxidant and antimicrobial activity of Cissus quadrangularis L. J. Med. Food. 6 (2), 99-105. doi:10.1089/109662003322233495

Choi, H. K., Kim, G. J., Yoo, H. S., Song, D. H., Chung, K. H., Lee, K. J., et al. (2019). Vitamin C activates osteoblastogenesis and inhibits osteoclastogenesis via Wnt/ $\beta$-catenin/ATF4 signaling pathways. Nutrients 11 (3), 506. doi:10.3390/ nu11030506

Choudhary, D., Kushwaha, P., Gautam, J., Kumar, P., Verma, A., Kumar, A., et al. (2016). Fast and long acting neoflavonoids dalbergin isolated from Dalbergia Sissoo heartwood is osteoprotective in ovariectomized model of osteoporosis: osteoprotective effect of Dalbergin. Biomed. Pharmacother. 83, 942-957. doi:10. 1016/j.biopha.2016.08.010

Choudhary, R., Chatterjee, A., Venkatraman, S. K., Koppala, S., Abraham, J., and Swamiappan, S. (2018). Antibacterial forsterite (Mg2SiO4) scaffold: a promising bioceramic for load bearing applications. Bioactive Mater. 3 (3), 218-224. doi:10.1016/j.bioactmat.2018.03.003

Chu, X., Wu, F., Sun, B., Zhang, M., Song, S., Zhang, P., et al. (2020). Genipin cross-linked carbon dots for antimicrobial, bioimaging and bacterial discrimination. Colloids Surf. B Biointerfaces 11, 930. doi:10.1016/j. colsurfb.2020.110930

Ciobanu, G., Bargan, A. M., and Luca, C. (2015). New bismuth-substituted hydroxyapatite nanoparticles for bone tissue engineering. JOM. 67 (11), 2534-2542. doi:10.1007/s11837-015-1467-8

Ciobanu, G., and Harja, M. (2019). Cerium-doped hydroxyapatite/collagen coatings on titanium for bone implants. Ceram. Int. 45 (2), 2852-2857. doi:10.1016/j.ceramint.2018.07.290

Coelho, C. C., Araújo, R., Quadros, P. A., Sousa, S. R., and Monteiro, F. J. (2019). Antibacterial bone substitute of hydroxyapatite and magnesium oxide to prevent dental and orthopaedic infections. Mater. Sci. Eng. C. 97, 529-538. doi:10.1016/j.msec.2018.12.059

Dai, Z., Dang, M., Zhang, W., Murugan, S., Teh, S. W., and Pan, H. (2019). Biomimetic hydroxyapatite/poly xylitol sebacic adibate/vitamin $\mathrm{K}$ nanocomposite for enhancing bone regeneration. Artif. Cells Nanomed. Biotechnol. 47 (1), 1898-1907. doi:10.1080/21691401.2019.1573183

Dave, K., and Gomes, V. G. (2019). Interactions at scaffold interfaces: effect of surface chemistry, structural attributes and bioaffinity. Mater. Sci. Eng. C. 105, 110078. doi:10.1016/j.msec.2019.110078
De Cesare, F., Di Mattia, E., Zussman, E., and Macagnano, A. (2019). A study on the dependence of bacteria adhesion on the polymer nanofibre diameter. Environ. Sci. Nano. 6 (3), 778-797. doi:10.1039/C8EN01237G

del Pozo, E. G., Collazos, J., Cartón, J. A., Camporro, D., and Asensi, V. (2018). Bacterial osteomyelitis: microbiological, clinical, therapeutic, and evolutive characteristics of 344 episodes. Rev. Española Quimioter. 31 (3), 217.

Dey, S., and Bishayi, B. (2016). Riboflavin along with antibiotics balances reactive oxygen species and inflammatory cytokines and controls Staphylococcus aureus infection by boosting murine macrophage function and regulates inflammation. J. Inflamm. 13 (1), 36. doi:10.1186/s12950-016-0145-0

Diez-Pascual, A. M., and Diez-Vicente, A. L. (2016). Poly (propylene fumarate)/ polyethylene glycol-modified graphene oxide nanocomposites for tissue engineering. ACS Appl. Mater. Interfaces. 8 (28), 17902-17914. doi:10.1021/ acsami.6b05635

Ding, L., Wang, H., Liu, D., Zeng, X. A., and Mao, Y. (2020). Bacteria capture and inactivation with functionalized multi-walled carbon nanotubes (MWCNTs). J. Nanosci. Nanotechnol. 20 (4), 2055-2062. doi:10.1166/ jnn.2020.17332

Diu, T., Faruqui, N., Sjöström, T., Lamarre, B., Jenkinson, H. F., Su, B., et al. (2014). Cicada-inspired cell-instructive nanopatterned arrays. Sci. Rep 4, 7122. doi:10. 1038/srep07122

Dixit, M., Raghuvanshi, A., Gupta, C. P., Kureel, J., Mansoori, M. N., Shukla, P., et al. (2015). Medicarpin, a natural pterocarpan, heals cortical bone defect by activation of notch and Wnt canonical signaling pathways. PloS One 10 (12), e0144541. doi:10.1371/journal.pone.0144541

Dixit, P., Chand, K., Khan, M. P., Siddiqui, J. A., Tewari, D., Ngueguim, F. T., et al. (2012). Phytoceramides and acylated phytosterol glucosides from Pterospermum acerifolium Willd. seed coat and their osteogenic activity. Phytochemistry 81, 117-125. doi:10.1016/j.phytochem.2012.06.005

Dixit, P., Khan, M. P., Swarnkar, G., Chattopadhyay, N., and Maurya, R. (2011). Osteogenic constituents from Pterospermum acerifolium Willd. flowers. Bioorg. Med. Chem. Lett. 21 (15), 4617-4621. doi:10.1016/j.bmcl.2011.05.087

Donlan, R. M. (2002). Biofilms: microbial life on surfaces. Emerg. Infect. Dis. 8 (9), 881. doi:10.3201/eid0809.020063

Drampalos, E., Mohammad, H. R., Kosmidis, C., Balal, M., Wong, J., and Pillai, A. (2018). Single stage treatment of diabetic calcaneal osteomyelitis with an absorbable gentamicin-loaded calcium sulphate/hydroxyapatite biocomposite: the Silo technique. Foot. 34, 40-44. doi:10.1016/j.foot.2017.11.011

Du, F., Yuan, J., Zhang, M., Li, J., Li, Z., Cao, M., et al. (2014). Nitrogen-doped carbon dots with heterogeneous multi-layered structures. RSC Adv. 4 (71), 37536-37541. doi:10.1039/C4RA06818A

Du, Y., Yu, M., Ge, J., Ma, P. X., Chen, X., and Lei, B. (2015). Development of a multifunctional platform based on strong, intrinsically photoluminescent and antimicrobial silica-poly (citrates)-based hybrid biodegradable elastomers for bone regeneration. Adv. Funct. Mater. 25 (31), 5016-5029. doi:10.1002/adfm. 201501712

Du, Z., Leng, H., Guo, L., Huang, Y., Zheng, T., Zhao, Z., et al. (2020). Calcium silicate scaffolds promoting bone regeneration via the doping of $\mathrm{Mg} 2+$ or $\mathrm{Mn} 2+$ ion. Compos. B Eng. 190, 107937. doi:10.1016/j.compositesb.2020.107937

Duan, S., Yang, X., Mei, F., Tang, Y., Li, X., Shi, Y., et al. (2015). Enhanced osteogenic differentiation of mesenchymal stem cells on poly (l-lactide) nanofibrous scaffolds containing carbon nanomaterials. J. Biomed. Mater. Res. 103 (4), 1424-1435. doi:10.1002/jbm.a.35283

Eltohamy, M., Kundu, B., Moon, J., Lee, H. Y., and Kim, H. W. (2018). Antibacterial zinc-doped calcium silicate cements: bone filler. Ceram. Int. 44 (11), 13031-13038. doi:10.1016/j.ceramint.2018.04.122

Faia-Torres, A. B., Charnley, M., Goren, T., Guimond-Lischer, S., Rottmar, M., Maniura-Weber, K., et al. (2015). Osteogenic differentiation of human mesenchymal stem cells in the absence of osteogenic supplements: a surface-roughness gradient study. Acta Biomater. 28, 64-75. doi:10.1016/j. actbio.2015.09.028

Faia-Torres, A. B., Guimond-Lischer, S., Rottmar, M., Charnley, M., Goren, T., Maniura-Weber, K., et al. (2014). Differential regulation of osteogenic differentiation of stem cells on surface roughness gradients. Biomaterials 35 (33), 9023-9032. doi:10.1016/j.biomaterials.2014.07.015

Fateme, R., Fatemeh, G., Sima, S., Moshaverinia, A., and Hasannia, S. (2019). New engineered fusion peptide with dual functionality: antibacterial and strong 
binding to hydroxyapatite. Int. J. Pept. Res. Therapeut. 1-11. doi:10.1007/ s10989-020-10030-w

Fayyazbakhsh, F., Solati-Hashjin, M., Keshtkar, A., Shokrgozar, M. A., Dehghan, M. M., and Larijani, B. (2017). Release behavior and signaling effect of vitamin D3 in layered double hydroxides-hydroxyapatite/gelatin bone tissue engineering scaffold: an in vitro evaluation. Colloids Surf. B Biointerfaces 158, 697-708. doi:10.1016/j.colsurfb.2017.07.004

Felice, B., Sánchez, M. A., Socci, M. C., Sappia, L. D., Gómez, M. I., Cruz, M. K., et al. (2018). Controlled degradability of PCL-ZnO nanofibrous scaffolds for bone tissue engineering and their antibacterial activity. Mater. Sci. Eng. C. 93, 724-738. doi:10.1016/j.msec.2018.08.009

Filipović, U., Dahmane, R. G., Ghannouchi, S., Zore, A., and Bohinc, K. (2020). Bacterial adhesion on orthopedic implants. Adv. Colloid Interface Sci. 20, 102228. doi:10.1016/j.cis.2020.102228

Florence, N. T., Huguette, S. T. S., Hubert, D. J., Raceline, G. K., Desire, D. D. P., Pierre, K., et al. (2017). Aqueous extract of Peperomia pellucida (L.) HBK accelerates fracture healing in Wistar rats. BMC Complem. Altern. Med. 17 (1), 188. doi:10.1186/s12906-017-1686-3

Foong, L. K., Foroughi, M. M., Mirhosseini, A. F., Safaei, M., Jahani, S., Mostafavi, M., et al. (2020). Applications of nano-materials in diverse dentistry regimes. RSC Adv. 10 (26), 15430-15460. doi:10.1039/D0RA00762E

Foroutan, F., McGuire, J., Gupta, P., Nikolaou, A., Kyffin, B. A., Kelly, N. L., et al. (2019). Antibacterial copper-doped calcium phosphate glasses for bone tissue regeneration. ACS Biomater. Sci. Eng. 5 (11), 6054-6062. doi:10.1021/ acsbiomaterials.9b01291

Geng, H., Wang, T., Cao, H., Zhu, H., Di, Z., and Liu, X. (2019). Antibacterial ability, cytocompatibility and hemocompatibility of fluorinated graphene. Colloids Surf. B Biointerfaces 173, 681-688. doi:10.1016/j.msec.2019.04.051

Ginebra, M. P., Espanol, M., Maazouz, Y., Bergez, V., and Pastorino, D. (2018). Bioceramics and bone healing. EFORT Open Rev. 3 (5), 173-183. doi:10.1302/ 2058-5241.3.170056

Glukhov, E., Stark, M., Burrows, L. L., and Deber, C. M. (2005). Basis for selectivity of cationic antimicrobial peptides for bacterial versus mammalian membranes. J. Biol. Chem. 280 (40), 33960-33967. doi:10. 1074/jbc.M507042200

Gnaneshwar, P. V., Sudakaran, S. V., Abisegapriyan, S., Sherine, J., Ramakrishna, S., Rahim, M. H. A., et al. (2019). Ramification of zinc oxide doped hydroxyapatite biocomposites for the mineralization of osteoblasts. Mater. Sci. Eng. C. 96, 337-346. doi:10.1016/j.msec.2018.11.033

Goodwin, D. G., Xia, Z., Gordon, T. B., Gao, C., Bouwer, E. J., and Fairbrother, D. H. (2016). Biofilm development on carbon nanotube/polymer nanocomposites. Environ. Sci.: Nano. 3 (3), 545-558. doi:10.1039/C5EN00277J

Gopi, D., Ramya, S., Rajeswari, D., Karthikeyan, P., and Kavitha, L. (2014). Strontium, cerium co-substituted hydroxyapatite nanoparticles: synthesis, characterization, antibacterial activity towards prokaryotic strains and in vitro studies. Colloid. Surface. Physicochem. Eng. Aspect. 451, 172-180. doi:10.1016/j.colsurfa.2014.03.035

Guarino, V., Scaglione, S., Sandri, M., Alvarez-Perez, M. A., Tampieri, A., Quarto, R., et al. (2014). MgCHA particles dispersion in porous PCL scaffolds: in vitro mineralization and in vivo bone formation. J. Tissue Eng. Regenerat. Med. 8 (4), 291-303. doi:10.1002/term.1521

Guo, J., Qin, J., Ren, Y., Wang, B., Cui, H., Ding, Y., et al. (2018). Antibacterial activity of cationic polymers: side-chain or main-chain type? Polym. Chem. 9 (37), 4611-4616. doi:10.1039/C8PY00665B

Halim, A., Liu, L., Ariyanti, A. D., Ju, Y., Luo, Q., and Song, G. (2019). Low-dose suspended graphene oxide nanosheets induce antioxidant response and osteogenic differentiation of bone marrow-derived mesenchymal stem cells via JNK-dependent FoxO1 activation. J. Mater. Chem. B. 7 (39), 5998-6009. doi:10.1039/C9TB01413F

Hasan, A., Lee, K., Tewari, K., Pandey, L. M., Messersmith, P. B., Faulds, K., et al. (2020a). Surface design for immobilization of an antimicrobial peptide mimic for efficient antibiofouling. Chem. Eur. J. 26 (26), 5789-5793. doi:10.1002/chem.202000746

Hasan, A., Saxena, V., Castelletto, V., Zimbitas, G., Seitsonen, J., Ruokolainen, J., et al. (2020b). Chain-end modifications and sequence arrangements of antimicrobial peptoids for mediating activity and nano-assembly. Front. Chem. 8. doi:10.3389/fchem.2020.00416

Hasan, A., Waibhaw, G., Saxena, V., and Pandey, L. M. (2018). Nano-biocomposite scaffolds of chitosan, carboxymethyl cellulose and silver nanoparticle modified cellulose nanowhiskers for bone tissue engineering applications. Int. J. Biol. Macromol. 111, 923-934. doi:10.1016/j.ijbiomac.2018.01.089

Hasan, J., Jain, S., and Chatterjee, K. (2017). Nanoscale topography on black titanium imparts multi-biofunctional properties for orthopedic applications. Sci. Rep. 7 (1), 1-13. doi:10.1038/srep41118

He, C. C., Hui, R. R., Tezuka, Y., Kadota, S., and Li, J. X. (2010). Osteoprotective effect of extract from Achyranthes bidentata in ovariectomized rats. J. Ethnopharmacol. 127 (2), 229-234. doi:10.1016/j.jep.2009.11.016

He, Y., Li, Y., Chen, G., Wei, C., Zhang, X., Zeng, B., et al. (2020). Concentrationdependent cellular behavior and osteogenic differentiation effect induced in bone marrow mesenchymal stem cells treated with magnetic graphene oxide. J. Biomed. Mater. Res. 108 (1), 50-60. doi:10.1002/adhm.201901495

Herscovitch, K., Dauletbaev, N., and Lands, L. C. (2014). Vitamin D as an antimicrobial and anti-inflammatory therapy for Cystic Fibrosis. Paediatr. Respir. Rev. 15 (2), 154-162. doi:10.1016/j.prrv.2013.11.002

Hezi-Yamit, A., Sullivan, C., Wong, J., David, L., Chen, M., Cheng, P., et al. (2009). Impact of polymer hydrophilicity on biocompatibility: implication for DES polymer design. J. Biomed. Mater. Res. Part A: Off. J. Soc. Biomater. Jpn Soc. Biomater. Austr. Soc. Biomater. Korean Soc. Biomater. 90 (1), 133-141. doi:10. 1002/jbm.a.32057

Hofstee, M. I., Muthukrishnan, G., Atkins, G. J., Riool, M., Thompson, K., Morgenstern, M., et al. (2020). Current concepts of osteomyelitis: from pathological mechanisms to advanced research methods. Am. J. Pathol. doi:10.1016/j.ajpath.2020.02.007

Huang, B., Vyas, C., Byun, J. J., El-Newehy, M., Huang, Z., and Bártolo, P. (2020). Aligned multi-walled carbon nanotubes with nanohydroxyapatite in a $3 \mathrm{D}$ printed polycaprolactone scaffold stimulates osteogenic differentiation. Mater. Sci. Eng. C 108, 110374. doi:10.1016/j.msec.2019.110374

Huang, B., Vyas, C., Roberts, I., Poutrel, Q. A., Chiang, W. H., Blaker, J. J., et al. (2019). Fabrication and characterisation of 3D printed MWCNT composite porous scaffolds for bone regeneration. Mater. Sci. Eng. C 98, 266-278. doi:10. 1016/j.msec.2018.12.100

Huang, Y., Hao, M., Nian, X., Qiao, H., Zhang, X., Zhang, X., et al. (2016). Strontium and copper co-substituted hydroxyapatite-based coatings with improved antibacterial activity and cytocompatibility fabricated by electrodeposition. Ceram. Int. 42 (10), 11876-11888. doi:10.1016/j.ceramint.2016.04.110

Huang, Y., Zha, G., Luo, Q., Zhang, J., Zhang, F., Li, X., et al. (2014). The construction of hierarchical structure on Ti substrate with superior osteogenic activity and intrinsic antibacterial capability. Sci. Rep. 4, 6172. doi:10.1038/srep06172

Humm, G., Noor, S., Bridgeman, P., David, M., and Bose, D. (2014). Adjuvant treatment of chronic osteomyelitis of the tibia following exogenous trauma using OSTEOSET $^{\circledR}$-T: a review of 21 patients in a regional trauma centre. Strategies Trauma Limb Reconstr. 9 (3), 157-161. doi:10.1007/s11751-014-0206-y

Ibrahim, M., Xue, Y., Ostermann, M., Sauter, A., Steinmueller-Nethl, D., Schweeberg, S., et al. (2018). In vitro cytotoxicity assessment of nanodiamond particles and their osteogenic potential. J. Biomed. Mater. Res. 106 (6), 1697-1707. doi:10.1002/jbm.a.36369

Iqbal, N., Kadir, M. R. A., Malek, N. A. N. N., Mahmood, N. H., Murali, M. R., and Kamarul, T. (2012). Rapid microwave assisted synthesis and characterization of nanosized silver-doped hydroxyapatite with antibacterial properties. Mater. Lett. 89, 118-122. doi:10.1016/j.matlet.2012.08.057

Jaidev, L. R., Kumar, S., and Chatterjee, K. (2017). Multi-biofunctional polymer graphene composite for bone tissue regeneration that elutes copper ions to impart angiogenic, osteogenic and bactericidal properties. Colloids Surf. B Biointerfaces. 159, 293-302. doi:10.1016/j.colsurfb.2017.07.083

Jatoi, A. W., Ogasawara, H., Kim, I. S., and Ni, Q. Q. (2020). Cellulose acetate/ multi-wall carbon nanotube/Ag nanofiber composite for antibacterial applications. Mater. Sci. Eng. C. 110, 110679. doi:10.1016/j.msec.2020.110679

Jin, N., Jin, N., Wang, Z., Liu, L., Meng, L., Li, D., et al. (2020). Osteopromotive carbon dots promote bone regeneration through the PERK-eIF2a-ATF4 pathway. Biomater. Sci. 8 (10), 2840-2852. doi:10.1039/D0BM00424C

Johnson, C. T., and García, A. J. (2015). Scaffold-based anti-infection strategies in bone repair. Ann. Biomed. Eng. 43 (3), 515-528. doi:10.1007/s10439-0141205-3

Jones, J. A., Chang, D. T., Meyerson, H., Colton, E., Kwon, I. K., Matsuda, T., et al. (2007). Proteomic analysis and quantification of cytokines and chemokines from biomaterial surface-adherent macrophages and foreign body giant cells. J. Biomed. Mater. Res. Part A: Off. J. Soc. Biomater. Jpn. Soc. 
Biomater. Austr. Soc. Biomater. Korean Soc. Biomater. 83 (3), 585-596. doi:10.1002/jbm.a.31221

Kaith, B. S., Sharma, R., and Kalia, S. (2015). Guar gum based biodegradable, antibacterial and electrically conductive hydrogels. Int. J. Biol. Macromol. 75, 266-275. doi:10.1016/j.ijbiomac.2015.01.046

Kallala, R., Harris, W. E., Ibrahim, M., Dipane, M., and McPherson, E. (2018). Use of Stimulan absorbable calcium sulphate beads in revision lower limb arthroplasty: safety profile and complication rates. Bone Joint Res. 7 (10), 570-579. doi:10.1302/2046-3758.710.BJR-2017-0319.R1

Karlsson, H. L., Toprak, M. S., and Fadeel, B. (2015). Toxicity of metal and metal oxide nanoparticles Handbook on the toxicology of metals. New York, NY: Academic Press, 75-112. doi:10.1016/B978-0-444-59453-2.00004-4

Karvande, A., Khedgikar, V., Kushwaha, P., Ahmad, N., Kothari, P., Verma, A., et al. (2017). Heartwood extract from Dalbergia sissoo promotes fracture healing and its application in ovariectomy-induced osteoporotic rats. J. Pharm. Pharmacol. 69 (10), 1381-1397. doi:10.1111/jphp.12764

Kashte, S., Jaiswal, A. K., and Kadam, S. (2017). Artificial bone via bone tissue engineering: current scenario and challenges. Tissue Eng. Regenerat. Med. 14 (1), 1-14. doi:10.1007/s13770-016-0001-6

Kaur, J., Rajkhowa, R., Afrin, T., Tsuzuki, T., and Wang, X. (2014). Facts and myths of antibacterial properties of silk. Biopolymers 101 (3), 237-245. doi:10.1002/ bip. 22323

Kelleher, S. M., Habimana, O., Lawler, J., O’reilly, B., Daniels, S., Casey, E., et al. (2016). Cicada wing surface topography: an investigation into the bactericidal properties of nanostructural features. ACS Appl. Mater. Interfaces. 8 (24), 14966-14974. doi:10.1021/acsami.5b08309

Khan, M. F., Dev, K., Lahiri, S., Dixit, M., Trivedi, R., Singh, D., et al. (2014). Osteogenic activity of natural diterpenoids isolated from Cupressus sempervirens fruits in calvarial derived osteoblast cells via differentiation and mineralization. Phytomedicine 21 (14), 1794-1800. doi:10.1016/j. phymed.2014.09.004

Khan, M. I., Akhtar, M. N., Ashraf, N., Najeeb, J., Munir, H., Awan, T. I., et al. (2020). Green synthesis of magnesium oxide nanoparticles using Dalbergia sissoo extract for photocatalytic activity and antibacterial efficacy. Appl. Nanosci doi:10.1007/s13204-020-01414-X

Khedgikar, V., Ahmad, N., Kushwaha, P., Gautam, J., Nagar, G. K., Singh, D., et al. (2015). Preventive effects of withaferin A isolated from the leaves of an Indian medicinal plant Withania somnifera (L.): comparisons with 17$\beta$-estradiol and alendronate. Nutrition. 31 (1), 205-213. doi:10.1016/j.nut. 2014.05.010

Khedgikar, V., Kushwaha, P., Ahmad, N., Gautam, J., Kumar, P., Maurya, R., et al. (2017). Ethanolic extract of Dalbergia sissoo promotes rapid regeneration of cortical bone in drill-hole defect model of rat. Biomed. Pharmacother. 86, 16-22. doi:10.1016/j.biopha.2016.11.140

Khedgikar, V., Kushwaha, P., Gautam, J., Verma, A., Changkija, B., Kumar, A., et al. (2013). Withaferin A: a proteasomal inhibitor promotes healing after injury and exerts anabolic effect on osteoporotic bone. Cell Death Dis. 4 (8), e778. doi:10.1038/cddis.2013.294

Kim, H., Mondal, S., Jang, B., Manivasagan, P., Moorthy, M. S., and Oh, J. (2018). Biomimetic synthesis of metal-hydroxyapatite (Au-HAp, Ag-HAp, Au-AgHAp): structural analysis, spectroscopic characterization and biomedical application. Ceram. Int. 44 (16), 20490-20500. doi:10.1016/j.ceramint.2018. 08.045

Kim, J., McKee, J. A., Fontenot, J. J., and Jung, J. P. (2019). Engineering tissue fabrication with machine intelligence: generating a blueprint for regeneration. Front. Bioeng. Biotechnol. 7, 443. doi:10.3389/fbioe.2019.00443

Kokubo, T., Pattanayak, D. K., Yamaguchi, S., Takadama, H., Matsushita, T., Kawai, T., et al. (2010). Positively charged bioactive Ti metal prepared by simple chemical and heat treatments. J. R. Soc. Interface. 7 (Suppl. 1_5), S503-S513. doi:10.1098/rsif.2010.0129.focus

Kuang, Z., Dai, G., Wan, R., Zhang, D., Zhao, C., Chen, C., et al. (2019). Osteogenic and antibacterial dual functions of a novel levofloxacin loaded mesoporous silica microspheres/nano-hydroxyapatite/polyurethane composite scaffold. Genes \& Dis. 90, 9014. doi:10.1016/j.gendis.2019.09.014

Kulanthaivel, S., Mishra, U., Agarwal, T., Giri, S., Pal, K., Pramanik, K., et al. (2015). Improving the osteogenic and angiogenic properties of synthetic hydroxyapatite by dual doping of bivalent cobalt and magnesium ion. Ceram. Int. 41 (9), 11323-11333. doi:10.1016/j.ceramint.2015.05.090
Kumar, S., Raj, S., Kolanthai, E., Sood, A. K., Sampath, S., and Chatterjee, K. (2015). Chemical functionalization of graphene to augment stem cell osteogenesis and inhibit biofilm formation on polymer composites for orthopedic applications. ACS Appl. Mater. Interfaces 7 (5), 3237-3252. doi:10.1021/am5079732

Kumar, S., Raj, S., Sarkar, K., and Chatterjee, K. (2016). Engineering a multibiofunctional composite using poly (ethylenimine) decorated graphene oxide for bone tissue regeneration. Nanoscale 8 (12), 6820-6836. doi:10.1039/ C5NR06906H

Kurtjak, M., Vukomanović, M., and Suvorov, D. (2017). Antibacterial nanocomposite of functionalized nanogold and gallium-doped hydroxyapatite. Mater. Lett. 193, 126-129. doi:10.1016/j.matlet.2017.01.092

Lan, W., Zhang, X., Xu, M., Zhao, L., Huang, D., Wei, X., et al. (2019). Carbon nanotube reinforced polyvinyl alcohol/biphasic calcium phosphate scaffold for bone tissue engineering. RSC Adv. 9 (67), 38998-39010. doi:10.1039/ C9RA08569F

Lee, F. H., Shen, P. C., Jou, I. M., Li, C. Y., and Hsieh, J. L. (2015). A populationbased 16-year study on the risk factors of surgical site infection in patients after bone grafting: a cross-sectional study in Taiwan. Medicine 94 (47). doi:10.1097/ MD.0000000000002034

Lee, N. Y., Hsueh, P. R., and Ko, W. C. (2019). Nanoparticles in the treatment of infections caused by multidrug-resistant organisms. Front. Pharmacol. 10, 1153. doi:10.3389/fphar.2019.01153

Leena, R. S., Vairamani, M., and Selvamurugan, N. (2017). Alginate/Gelatin scaffolds incorporated with Silibinin-loaded Chitosan nanoparticles for bone formation in vitro. Colloids Surf. B Biointerfaces. 158, 308-318. doi:10.1016/j. colsurfb.2017.06.048

Lei, T., Zhang, W., Qian, H., Lim, P. N., San Thian, E., Lei, P., et al. (2019). Siliconincorporated nanohydroxyapatite-reinforced poly ( $\varepsilon$-caprolactone) film to enhance osteogenesis for bone tissue engineering applications. Colloids Surf. B Biointerfaces., 110714. doi:10.1016/j.colsurfb.2019.110714

Li, F., Su, Y., Pi, G., Ma, P. X., and Lei, B. (2018). Biodegradable, Biomimetic elastomeric, photoluminescent, and broad-spectrum antibacterial polycitrate-polypeptide-based membrane toward multifunctional biomedical implants. ACS Biomater. Sci. Eng. 4 (8), 3027-3035. doi:10. 1021/acsbiomaterials. 8 b00660

Li, H., Song, X., Li, B., Kang, J., Liang, C., Wang, H., et al. (2017). Carbon nanotubereinforced mesoporous hydroxyapatite composites with excellent mechanical and biological properties for bone replacement material application. Mater. Sci. Eng. C. 77, 1078-1087. doi:10.1016/j.msec.2017.04.048

Li, J., Mou, X., Qiu, J., Wang, S., Wang, D., Sun, D., et al. (2015). Surface charge regulation of osteogenic differentiation of mesenchymal stem cell on polarized ferroelectric crystal substrate. Adv. Healthc. Mater. 4 (7), 998-1003. doi:10. 1002/adhm.201500032

Li, M., Ma, Z., Zhu, Y., Xia, H., Yao, M., Chu, X., et al. (2016a). Toward a molecular understanding of the antibacterial mechanism of copper-bearing titanium alloys against staphylococcus aureus. Adv. Healthc. Mater. 5 (5), 557-566. doi:10.1002/adhm.201500712

Li, Y., Liu, X., Tan, L., Ren, L., Wan, P., Hao, Y., et al. (2016b). Enoxacin-loaded poly (lactic-co-glycolic acid) coating on porous magnesium scaffold as a drug delivery system: antibacterial properties and inhibition of osteoclastic bone resorption. J. Mater. Sci. Technol. 32 (9), 865-873. doi:10.1016/j.jmst.2016. 07.013

Li, P., Han, F., Cao, W., Zhang, G., Li, J., Zhou, J., et al. (2020a). Carbon quantum dots derived from lysine and arginine simultaneously scavenge bacteria and promote tissue repair. Appl. Mater. Today. 19, 100601. doi:10.1016/j.apmt.2020. 100601

Li, P., Liu, S., Cao, W., Zhang, G., Yang, X., Gong, X., et al. (2020b). Low-toxicity carbon quantum dots derived from gentamicin sulfate to combat antibiotic resistance and eradicate mature biofilms. Chem. Commun. 56 (15), 2316-2319. doi:10.1039/C9CC09223D

Li, P., Liu, S., Zhang, G., Yang, X., Cao, W., Gong, X., et al. (2020c). Design of pHresponsive dissociable nanosystem based on carbon dots with enhanced antibiofilm property and excellent biocompatibility. ACS Appl. Bio Mater. 3 (2), 1105-1115. doi:10.1021/acsabm.9b01053

Li, X., Zhao, J., Hong, X., Yang, Y., Tang, X., Zhu, Y., et al. (2020d). Calcinationdependent surface defect variation and antibacterial activity of magnesium oxide nanoplates. ChemistrySelect 5 (11), 3201-3207. doi:10.11002/slct.201904853 
Liao, S., Tang, Y., Chu, C., Lu, W., Baligen, B., Man, Y., et al. (2020). Application of green tea extracts epigallocatechin-3-gallate in dental materials: recent progress and perspectives. J. Biomed. Mater. Res. doi:10.1002/jbm.a.36991

Lin, W. C., Yao, C., Huang, T. Y., Cheng, S. J., and Tang, C. M. (2019). Long-term in vitro degradation behavior and biocompatibility of polycaprolactone/cobaltsubstituted hydroxyapatite composite for bone tissue engineering. Dent. Mater. 35 (5), 751-762. doi:10.1016/j.dental.2019.02.023

Lin, Y., Xiao, W., Bal, B. S., and Rahaman, M. N. (2016). Effect of copper-doped silicate 13-93 bioactive glass scaffolds on the response of MC3T3-E1 cells in vitro and on bone regeneration and angiogenesis in rat calvarial defects in vivo. Mater. Sci. Eng. C. 67, 440-452. doi:10.1016/j.msec.2016.05.073

Lin, Y., Yang, Z., and Cheng, J. (2007). Preparation, characterization and antibacterial property of cerium substituted hydroxyapatite nanoparticles. J. Rare Earths. 25 (4), 452-456. doi:10.1016/S1002-0721(07)60455-4

Linklater, D. P., Juodkazis, S., Crawford, R., and Ivanova, E. (2019). Mechanical inactivation of Staphylococcus aureus and Pseudomonas aeruginosa by titanium substrata with hierarchical surface structures. Materialia 5, 100197. doi:10. 1016/j.mtla.2018.100197

Liu, W., Li, C., Ren, Y., Sun, X., Pan, W., Li, Y., et al. (2016). Carbon dots: surface engineering and applications. J. Mater. Chem. B 4 (35), 5772-5788. doi:10.1039/ C6TB00976

Liu, Y., Zheng, Y., and Hayes, B. (2017). Degradable, absorbable or resorbable-what is the best grammatical modifier for an implant that is eventually absorbed by the body?. Science China Materials 60 (5), 377-391. doi:10.1007/s40843-017-9023-9

Liu, W., Zou, Z., Zhou, L., Liu, H., Wen, W., Zhou, C., et al. (2019). Synergistic effect of functionalized poly (1-lactide) with surface-modified $\mathrm{MgO}$ and chitin whiskers on osteogenesis in vivo and in vitro. Mater. Sci. Eng. C. 103, 109851. doi:10.1016/j.msec.2019.109851

Liu, L., Zhang, Y., Li, C., Cao, J., He, E., Wu, X., et al. (2020a). Facile preparation $\mathrm{PCL} /$ modified nano $\mathrm{ZnO}$ organic-inorganic composite and its application in antibacterial materials. J. Polym. Res. 27 (3), 1-11. doi:10.1007/s10965-02002046-z

Liu, X., He, X., Jin, D., Wu, S., Wang, H., Yin, M., et al. (2020b). A biodegradable multifunctional nanofibrous membrane for periodontal tissue regeneration. Acta Biomater. doi:10.1016/j.actbio.2020.03.044

Lovati, A. B., Bottagisio, M., Maraldi, S., Violatto, M. B., Bortolin, M., De Vecchi, E., et al. (2018). Vitamin E phosphate coating stimulates bone deposition in implant-related infections in a rat model. Clin. Orthop. Relat. Res. 476 (6), 1324. doi:10.1097/01.blo.0000534692.41467.02

Lu, L., Hu, W., Tian, Z., Yuan, D., Yi, G., Zhou, Y., et al. (2019). Developing natural products as potential anti-biofilm agents. Chinese medicine 14 (1), 11. doi:10. 1186/s13020-019-0232-2

Lu, Y., Li, L., Li, M., Lin, Z., Wang, L., Zhang, Y., et al. (2018). Zero-dimensional carbon dots enhance bone regeneration, osteosarcoma ablation, and clinical bacterial eradication. Bioconjug. Chem. 29 (9), 2982-2993. doi:10.1021/acs. bioconjchem. 8 b00400

Luo, J., Zhang, X., Ong'achwa Machuki, J., Dai, C., Li, Y., Guo, K., et al. (2018). Three-dimensionally $\mathrm{N}$-doped graphene-hydroxyapatite/agarose as an osteoinductive scaffold for enhancing bone regeneration. ACS Appl. Bio Mater. 2 (1), 299-310. doi:10.1021/acsabm.8b00599

Luu, T. U., Gott, S. C., Woo, B. W., Rao, M. P., and Liu, W. F. (2015). Micro-and nanopatterned topographical cues for regulating macrophage cell shape and phenotype. ACS Appl. Mater. Interfaces 7 (51), 28665-28672. doi:10.1021/ acsami.5b10589

Madannejad, R., Shoaie, N., Jahanpeyma, F., Darvishi, M. H., Azimzadeh, M., and Javadi, H. (2019). Toxicity of carbon-based nanomaterials: reviewing recent reports in medical and biological systems. Chem. Biol. Interact. 307, 206-222. doi:10.1016/j.cbi.2019.04.036

Mahamuni-Badiger, P. P., Patil, P. M., Badiger, M. V., Patel, P. R., Thorat-Gadgil, B. S., Pandit, A., et al. (2020). Biofilm formation to inhibition: role of zinc oxidebased nanoparticles. Mater. Sci. Eng. C. 108, 110319. doi:10.1016/j.msec.2019. 110319

Majeed, F. A., Munir, H., Rashid, R., and Zubair, M. T. (2019). Antimicrobial, cytotoxicity, mutagenicity and anti-epileptic potential of ethanol extracts of a multipurpose medicinal plant Dalbergia sissoo. Biocatal. Agric. Biotechnol. 19, 101155. doi:10.1016/j.bcab.2019.101155
Makowski, M., Silva, Í. C., Pais do Amaral, C., Gonçalves, S., and Santos, N. C. (2019). Advances in lipid and metal nanoparticles for antimicrobial peptide delivery. Pharmaceutics 11 (11), 588. doi:10.3390/pharmaceutics11110588

Mansoori, M. N., Raghuvanshi, A., Shukla, P., Awasthi, P., Trivedi, R., Goel, A., et al. (2020). Medicarpin prevents arthritis in post-menopausal conditions by arresting the expansion of TH17 cells and pro-inflammatory cytokines. Int. Immunopharm. 82, 106299. doi:10.1016/j.intimp.2020.106299

Martel-Estrada, S. A., Rodríguez-Espinoza, B., Santos-Rodríguez, E., JiménezVega, F., García-Casillas, P. E., Martínez-Pérez, C. A., et al. (2015). Biocompatibility of chitosan/Mimosa tenuiflora scaffolds for tissue engineering. J. Alloys Compd. 643, S119-S123. doi:10.1016/j.jallcom.2015. 01.034

Martin, V., Ribeiro, I. A., Alves, M. M., Gonçalves, L., Claudio, R. A., Grenho, L., et al. (2019). Engineering a multifunctional 3D-printed PLA-collagenminocycline-nanoHydroxyapatite scaffold with combined antimicrobial and osteogenic effects for bone regeneration. Mater. Sci. Eng. C. 101, 15-26. doi:10. 1016/j.msec.2019.03.056

Maurya, R., Yadav, D. K., Singh, G., Bhargavan, B., Murthy, P. N., Sahai, M., et al. (2009). Osteogenic activity of constituents from Butea monosperma. Bioorg. Med. Chem. Lett. 19 (3), 610-613. doi:10.1016/j.bmcl.2008.12.064

Mehrjou, B., Mo, S., Dehghan-Baniani, D., Wang, G., Qasim, A. M., and Chu, P. K. (2019). Antibacterial and cytocompatible nanoengineered silk-based materials for orthopedic implants and tissue engineering. ACS Appl. Mater. Interfaces 11 (35), 31605-31614. doi:10.1021/acsami.9b09066

Merrifield, L. S., and Yang, H. Y. (1965). Factors affecting the antimicrobial activity of vitamin K5. Appl. Microbiol. 13 (5), 766-770.

Misra, S. K., Philip, S. E., Chrzanowski, W., Nazhat, S. N., Roy, I., Knowles, J. C., et al. (2009). Incorporation of vitamin $\mathrm{E}$ in poly (3hydroxybutyrate)/Bioglass composite films: effect on surface properties and cell attachment. J. R. Soc. Interface 6 (33), 401-409. doi:10.11098/rsif.2008.0278

Mohammed, H., Kumar, A., Bekyarova, E., Al-Hadeethi, Y., Zhang, X., Chen, M., et al. (2020). Antimicrobial mechanisms and effectiveness of graphene and graphene-functionalized biomaterials. A scope review. Front. Bioeng. Biotechnol. 8, 465. doi:10.3389/fbioe.2020.00465

Mohammed, M. K., Ahmed, D. S., and Mohammad, M. R. (2019). Studying antimicrobial activity of carbon nanotubes decorated with metal-doped $\mathrm{ZnO}$ hybrid materials. Mater. Res. Express. 6 (5), 055404. doi:10.1088/2053-1591/ ab0687

Mohan, P., and Mala, R. (2019). Comparative antibacterial activity of magnetic iron oxide nanoparticles synthesized by biological and chemical methods against poultry feed pathogens. Mater. Res. Express. 6 (11), 115077. doi:10. 1088/2053-1591/ab4964

Morais, D. S., Coelho, J., Ferraz, M. P., Gomes, P. S., Fernandes, M. H., Hussain, N. S., et al. (2014). Samarium doped glass-reinforced hydroxyapatite with enhanced osteoblastic performance and antibacterial properties for bone tissue regeneration. J. Mater. Chem. B 2 (35), 5872-5881. doi:10.1039/ C4TB00484A

Mousavi, S., Bereswill, S., and Heimesaat, M. M. (2019). Immunomodulatory and antimicrobial effects of vitamin C. Eur. J. Microbiol. Immunol. 9 (3), 73-79. doi:10.1556/1886.2019.00016

Münchow, E. A., Albuquerque, M. T. P., Zero, B., Kamocki, K., Piva, E., Gregory, R. L., et al. (2015). Development and characterization of novel ZnO-loaded electrospun membranes for periodontal regeneration. Dent. Mater. 31 (9), 1038-1051. doi:10.1016/j.dental.2015.06.004

Nagareddy, P. R., and Lakshmana, M. (2006). Withania somnifera improves bone calcification in calcium-deficient ovariectomized rats. J. Pharm. Pharmacol. 58 (4), 513-519. doi:10.1211/jpp.58.4.0011

Narayanan, A., Raja, S., Ponmurugan, K., Kandekar, S., Natarajaseenivasan, K., Maripandi, A., et al. (2011). Antibacterial activity of selected medicinal plants against multiple antibiotic resistant uropathogens: a study from Kolli Hills, Tamil Nadu, India. Benef. Microbes. 2 (3), 235-243. doi:10.3920/BM2010.0033

Nejadnik, M. R., van der Mei, H. C., Norde, W., and Busscher, H. J. (2008). Bacterial adhesion and growth on a polymer brush-coating. Biomaterials 29 (30), 4117-4121. doi:10.1016/j.biomaterials.2008.07.014

Neto, A. S., and Ferreira, J. M. (2018). Synthetic and marine-derived porous scaffolds for bone tissue engineering. Materials 11 (9), 1702. doi:10.3390/ ma11091702 
Nett, J. E., Cain, M. T., Crawford, K., and Andes, D. R. (2011). Optimizing a Candida biofilm microtiter plate model for measurement of antifungal susceptibility by tetrazolium salt assay. J. Clin. Microbiol. 49 (4), 1426-1433. doi:10.1128/JCM.02273-10

Ngueguim, F. T., Khan, M. P., Donfack, J. H., Tewari, D., Dimo, T., Kamtchouing, P., et al. (2013). Ethanol extract of Peperomia pellucida (Piperaceae) promotes fracture healing by an anabolic effect on osteoblasts. J. Ethnopharmacol. 148 (1), 62-68. doi:10.1016/j.jep.2013.03.063

Nguyen, D. H., Bazaka, O., Bazaka, K., Crawford, R. J., and Ivanova, E. P. (2020). Three-dimensional hierarchical Wrinkles on polymer films: from chaotic to ordered antimicrobial topographies. Trends Biotechnol. doi:10.1016/j.tibtech. 2019.12.004

Nostro, A., Cellini, L., Di Giulio, M., D’Arrigo, M., Marino, A., Blanco, A. R., et al. (2012). Effect of alkaline $\mathrm{pH}$ on staphylococcal biofilm formation. Apmis. 120 (9), 733-742. doi:10.1111/j.1600-0463.2012.02900.x

Ofudje, E. A., Adeogun, A. I., Idowu, M. A., and Kareem, S. O. (2019). Synthesis and characterization of $\mathrm{Zn}$-Doped hydroxyapatite: scaffold application, antibacterial and bioactivity studies. Heliyon. 5 (5), e01716. doi:10.1016/j. heliyon.2019.e01716

Ohgaki, M., Kizuki, T., Katsura, M., and Yamashita, K. (2001). Manipulation of selective cell adhesion and growth by surface charges of electrically polarized hydroxyapatite. J. Biomed. Mater. Res. Off. J. Soc. Biomater. 57 (3), 366-373. doi:10.1002/1097-4636(20011205)57:3<366::AID-JBM1179>3.0.CO;2-X

Orchard, T. S., Larson, J. C., Alghothani, N., Bout-Tabaku, S., Cauley, J. A., Chen, Z., et al. (2014). Magnesium intake, bone mineral density, and fractures: results from the Women's Health Initiative Observational Study. Am. J. Clin. Nutr. 99 (4), 926-933. doi:10.3945/ajcn.113.067488

Orsuwan, A., Kwon, S., Bumbudsanpharoke, N., and Ko, S. (2019). Novel LDPEriboflavin composite film with dual function of broad-spectrum light barrier and antimicrobial activity. Food Contr. 100, 176-182. doi:10.1016/j.foodcont. 2019.01.012

Ottaway, P. B. (2010). Stability of vitamins during food processing and storage. Chemical deterioration and physical instability of food and beverages. New York, NY: Woodhead Publishing, 539-560. doi:10.1533/9781845699260. 3.539

Ouyang, L., Deng, Y., Yang, L., Shi, X., Dong, T., Tai, Y., et al. (2018). Grapheneoxide-decorated microporous polyetheretherketone with superior antibacterial capability and in vitro osteogenesis for orthopedic implant. Macromol. Biosci. 18 (6), 1800036. doi:10.1002/mabi.201800036

O'Connor, J. P., Kanjilal, D., Teitelbaum, M., Lin, S. S., and Cottrell, J. A. (2020). Zinc as a therapeutic agent in bone regeneration. Materials 13 (10), 2211. doi:10.3390/ma13102211

O’Neill, E., Awale, G., Daneshmandi, L., Umerah, O., and Lo, K. W. H. (2018). The roles of ions on bone regeneration. Drug Discov. Today 23 (4), 879-890. doi:10. 1016/j.drudis.2018.01.049

Pacelli, S., Maloney, R., Chakravarti, A. R., Whitlow, J., Basu, S., Modaresi, S., et al. (2017). Controlling adult stem cell behavior using nanodiamond-reinforced hydrogel: implication in bone regeneration therapy. Sci. Rep. 7 (1), 1-15. doi:10. 1038/s41598-017-06028-y

Panda, S. K., and Dutta, S. K. (2011). Antibacterial activity from bark extracts of Pterospermum acerifolium (L.) Willd. Int. J. Pharmaceut. Sci. Res. 2 (3), 584. doi:10.13040/IJPSR.0975-8232.2(3).584-95

Parvathi, K., Krishnan, A. G., Anitha, A., Jayakumar, R., and Nair, M. B. (2018). Poly (L-lactic acid) nanofibers containing Cissus quadrangularis induced osteogenic differentiation in vitro. Int. J. Biol. Macromol. 110, 514-521. doi:10.1016/j.ijbiomac.2017.11.094

Pasquet, J., Chevalier, Y., Pelletier, J., Couval, E., Bouvier, D., and Bolzinger, M. A. (2014). The contribution of zinc ions to the antimicrobial activity of zinc oxide. Colloid. Surface. Physicochem. Eng. Aspect. 457, 263-274. doi:10.1016/j.colsurfa. 2014.05.057

Patel, K. D., Kim, T. H., Mandakhbayar, N., Singh, R. K., Jang, J. H., Lee, J. H., et al. (2020). Coating biopolymer nanofibers with carbon nanotubes accelerates tissue healing and bone regeneration through orchestrated cell-and tissueregulatory responses. Acta Biomater. doi:10.1016/j.actbio.2020.03.012

Pattanayak, D. K., Yamaguchi, S., Matsushita, T., Nakamura, T., and Kokubo, T. (2012). Apatite-forming ability of titanium in terms of $\mathrm{pH}$ of the exposed solution. J. R. Soc. Interface 9 (74), 2145-2155. doi:10.1098/ rsif.2012.0107
Pidhatika, B., Möller, J., Benetti, E. M., Konradi, R., Rakhmatullina, E., Mühlebach, A., et al. (2010). The role of the interplay between polymer architecture and bacterial surface properties on the microbial adhesion to polyoxazoline-based ultrathin films. Biomaterials 31 (36), 9462-9472. doi:10.1016/j.biomaterials. 2010.08.033

Prado-Prone, G., Silva-Bermudez, P., Bazzar, M., Focarete, M. L., Rodil, S. E., VidalGutiérrez, X., et al. (2020). Antibacterial composite membranes of polycaprolactone/gelatin loaded with zinc oxide nanoparticles for guided tissue regeneration. Biomed. Mater. 15 (3), 035006. doi:10.1088/1748-605X/ab70ef

Priyadarshini, B., Anjaneyulu, U., and Vijayalakshmi, U. (2017). Preparation and characterization of sol-gel derived $\mathrm{Ce} 4+$ doped hydroxyapatite and its in vitro biological evaluations for orthopedic applications. Mater. Des. 119, 446-455. doi:10.1016/j.matdes.2017.01.095

Qiao, H., Song, G., Huang, Y., Yang, H., Han, S., Zhang, X., et al. (2019). Si, Sr, Ag co-doped hydroxyapatite/TiO 2 coating: enhancement of its antibacterial activity and osteoinductivity. RSC Adv. 9 (24), 13348-13364. doi:10.1039/ C9RA01168D

Qiao, Y., Liu, X., Li, B., Han, Y., Zheng, Y., Yeung, K. W. K., et al. (2020). Treatment of MRSA-infected osteomyelitis using bacterial capturing, magnetically targeted composites with microwave-assisted bacterial killing. Nat. Commun. 11 (1), 1-13. doi:10.1038/s41467-020-18268-0

Qiu, J., Geng, H., Wang, D., Qian, S., Zhu, H., Qiao, Y., et al. (2017). Layer-number dependent antibacterial and osteogenic behaviors of graphene oxide electrophoretic deposited on titanium. ACS Appl. Mater. Interfaces. 9 (14), 12253-12263. doi:10.1021/acsami.7b00314

Qiu, J., Qian, W., Zhang, J., Chen, D., Yeung, K. W., and Liu, X. (2019). Minocycline hydrochloride loaded graphene oxide enables enhanced osteogenic activity in the presence of Gram-positive bacteria, Staphylococcus aureus. J. Mater. Chem. B. 7 (22), 3590-3598. doi:10.1039/c9tb00405j

Qu, H., Fu, H., Han, Z., and Sun, Y. (2019). Biomaterials for bone tissue engineering scaffolds: a review. RSC Adv. 9 (45), 26252-26262. doi:10.1039/c9ra05214c

Quelemes, P. V., de Araújo, A. R., Plácido, A., Delerue-Matos, C., Maciel, J. S., Bessa, L. J., et al. (2017). Quaternized cashew gum: an anti-staphylococcal and biocompatible cationic polymer for biotechnological applications. Carbohydr. Polym. 157, 567-575. doi:10.1016/j.carbpol.2016.10.026

Rabea, E. I., Badawy, M. E. T., Stevens, C. V., Smagghe, G., and Steurbaut, W. (2003). Chitosan as antimicrobial agent: applications and mode of action. Biomacromolecules 4 (6), 1457-1465. doi:10.1021/bm034130m

Raghavan, R. N., Somanathan, N., and Sastry, T. P. (2013). Evaluation of phytochemical-incorporated porous polymeric sponges for bone tissue engineering: a novel perspective. Proc. IME H J. Eng. Med. 227 (8), 859-865. doi:10.1177/0954411913489804

Raghunath, A., and Perumal, E. (2017). Metal oxide nanoparticles as antimicrobial agents: a promise for the future. Int. J. Antimicrob. Agents. 49 (2), 137-152. doi:10.1016/j.ijantimicag.2016.11.011

Rahmani, A., Hashemi-Najafabadi, S., Eslaminejad, M. B., Bagheri, F., and Sayahpour, F. A. (2019). The effect of modified electrospun PCL-nHA$\mathrm{nZnO}$ scaffolds on osteogenesis and angiogenesis. J. Biomed. Mater. Res. 107 (9), 2040-2052. doi:10.1002/jbm.a.36717

Ramakrishna, E., Dev, K., Kothari, P., Tripathi, A. K., Trivedi, R., and Maurya, R. (2017). Phytochemical investigation of Kigelia pinnata leaves and identification of osteogenic agents. Med. Chem. Res. 26 (5), 940-946. doi:10.1007/s00044-017-1807-z

Ran, H. H., Cheng, X., Bao, Y. W., Hua, X. W., Gao, G., Zhang, X., et al. (2019). Multifunctional quaternized carbon dots with enhanced biofilm penetration and eradication efficiencies. J. Mater. Chem. B. 7 (33), 5104-5114. doi:10.1039/ C9TB00681H

Rao, Y., Wang, W., Tan, F., Cai, Y., Lu, J., and Qiao, X. (2013). Influence of different ions doping on the antibacterial properties of $\mathrm{MgO}$ nanopowders. Appl. Surf. Sci. 284, 726-731. doi:10.1016/j.apsusc.2013.08.001

Rasool, M., and Varalakshmi, P. (2007). Protective effect of Withania somnifera root powder in relation to lipid peroxidation, antioxidant status, glycoproteins and bone collagen on adjuvant-induced arthritis in rats. Fundam. Clin. Pharmacol. 21 (2), 157-164. doi:10.1111/j.1472-8206.2006.00461.x

Rau, J. V., Curcio, M., Raucci, M. G., Barbaro, K., Fasolino, I., Teghil, R., et al. (2019). Cu-releasing bioactive glass coatings and their in vitro properties. ACS Appl. Mater. Interfaces 11 (6), 5812-5820. doi:10.1021/acsami.8b19082

Rawat, P., Kumar, M., Sharan, K., Chattopadhyay, N., and Maurya, R. (2009). Ulmosides A and B: flavonoid 6-C-glycosides from Ulmus wallichiana, 
stimulating osteoblast differentiation assessed by alkaline phosphatase. Bioorg. Med. Chem. Lett. 19 (16), 4684-4687. doi:10.1016/j.bmcl.2009.06.074

Rifai, A., Tran, N., Reineck, P., Elbourne, A., Mayes, E., Sarker, A., et al. (2019). Engineering the interface: nanodiamond coating on $3 \mathrm{D}$-printed titanium promotes mammalian cell growth and inhibits Staphylococcus aureus colonization. ACS Appl. Mater. Interfaces 11 (27), 24588-24597. doi:10.1021/acsami.9b07064

Roh, H. S., Lee, C. M., Hwang, Y. H., Kook, M. S., Yang, S. W., Lee, D., et al. (2017). Addition of $\mathrm{MgO}$ nanoparticles and plasma surface treatment of three-dimensional printed polycaprolactone/hydroxyapatite scaffolds for improving bone regeneration. Mater. Sci. Eng. C. 74, 525-535. doi:10.1016/j.msec.2016.12.054

Saha, S., and Ghosh, S. (2012). Tinospora cordifolia: one plant, many roles. Ancient Sci. Life. 31 (4), 151. doi:10.4103/0257-7941.107344

Sahariah, P., and Masson, M. (2017). Antimicrobial chitosan and chitosan derivatives: a review of the structure-activity relationship. Biomacromolecules 18 (11), 3846-3868. doi:10.1021/acs.biomac.7b01058

Sakthi, P. S., Ratha, I., Adarsh, T., Anand, A., Sinha, P. K., Diwan, P., et al. (2018). Use of dinitrosalicylic acid reagent for determination of reducing sugar. J. Mater. Res. 33 (2), 178-190. doi:10.1557/jmr.2017.442

Samadian, H., Farzamfar, S., Vaez, A., Ehterami, A., Bit, A., Alam, M., et al. (2020). A tailored polylactic acid/polycaprolactone biodegradable and bioactive $3 \mathrm{D}$ porous scaffold containing gelatin nanofibers and Taurine for bone regeneration. Sci. Rep. 10 (1), 1-12. doi:10.1038/s41598-02070155-2

Sánchez-López, E., Gomes, D., Esteruelas, G., Bonilla, L., Lopez-Machado, A. L., Galindo, R., et al. (2020). Metal-based nanoparticles as antimicrobial agents: an overview. Nanomaterials 10 (2), 292. doi:10.3390/nano10020292

Sarkar, N., Morton, H., and Bose, S. (2020). Effects of vitamin C on osteoblast proliferation and osteosarcoma inhibition using plasma coated hydroxyapatite on titanium implants. Surf. Coating. Technol. 125793. doi:10.1016/j.surfcoat. 2020.12579310.1038/s41598-020-70155-2

Sattary, M., Rafienia, M., Kazemi, M., Salehi, H., and Mahmoudzadeh, M. (2019). Promoting effect of nano hydroxyapatite and vitamin D3 on the osteogenic differentiation of human adipose-derived stem cells in polycaprolactone/gelatin scaffold for bone tissue engineering. Mater. Sci. Eng. C. 97, 141-155. doi:10. 1016/j.msec.2018.12.030

Saviane, A., Romoli, O., Bozzato, A., Freddi, G., Cappelletti, C., Rosini, E., et al. (2018). Intrinsic antimicrobial properties of silk spun by genetically modified silkworm strains. Transg. Res. 27 (1), 87-101. doi:10.1007/s11248-0180059-0

Saxena, V., Chandra, P., and Pandey, L. M. (2018). Design and characterization of novel Al-doped $\mathrm{ZnO}$ nanoassembly as an effective nanoantibiotic. Appl. Nanosci. 8 (8), 1925-1941. doi:10.1007/s13204-018-0863-0

Saxena, V., and Pandey, L. M. (2020). Bimetallic assembly of Fe (III) doped ZnO as an effective nanoantibiotic and its ROS independent antibacterial mechanism. J. Trace Elem. Med. Biol. Organ Soc. Miner. Trace Elem. (GMS). 57, 126416. doi:10.1016/j.jtemb.2019.126416

Scherping, S. C., and Aaron, A. D. (2007). "Orthopedic infections," in Essentials of orthopedic surgery. Editors S. W. Wiesel and J. N. Delahay (New York, NY: Springer). doi:10.1007/978-0-387-38328-6_3

Schmitt, S. K. (2017). Osteomyelitis. Infect. Dis. Clin. 31 (2), 325-338. doi:10.1016/j. idc.2017.01.010

Selim, S. A., Adam, M. E., Hassan, S. M., and Albalawi, A. R. (2014). Chemical composition, antimicrobial and antibiofilm activity of the essential oil and methanol extract of the Mediterranean cypress (Cupressus sempervirens L.). BMC Complem. Alternat. Med. 14 (1), 179. doi:10.1186/1472-6882-14-179

Shahrouzifar, M. R., Salahinejad, E., and Sharif, E. (2019). Co-incorporation of strontium and fluorine into diopside scaffolds: bioactivity, biodegradation and cytocompatibility evaluations. Mater. Sci. Eng. C. 103, 109752. doi:10.1016/j.msec.2019.109752

Shahrouzifar, M. R., and Salahinejad, E. (2019). Strontium doping into diopside tissue engineering scaffolds. Ceram. Int. 45 (8), 10176-10181. doi:10.1016/j. ceramint.2019.02.067

Shahzad, S., Ashraf, M. A., Sajid, M., Shahzad, A., Rafique, A., and Mahmood, M. S. (2018). Evaluation of synergistic antimicrobial effect of vitamins (A, B1, B2, B6, B12, C, D, E and K) with antibiotics against resistant bacterial strains. J. Global Antimicrob. Resist. 13, 231-236. doi:10.1016/j.jgar.2018.01.005

Shao, D., Lu, M., Xu, D., Zheng, X., Pan, Y., Song, Y., et al. (2017). Carbon dots for tracking and promoting the osteogenic differentiation of mesenchymal stem cells. Biomater. Sci. 5 (9), 1820-1827. doi:10.1039/C7BM00358G
Sheikh, L., Sinha, S., Singhababu, Y. N., Verma, V., Tripathy, S., and Nayar, S. (2018) Traversing the profile of biomimetically nanoengineered iron substituted hydroxyapatite: synthesis, characterization, property evaluation, and drug release modeling. RSC Adv. 8 (35), 19389-19401. doi:10.1039/C8RA01539B

Shi, F., Liu, Y., Zhi, W., Xiao, D., Li, H., Duan, K., et al. (2017). The synergistic effect of micro/nano-structured and Cu2+-doped hydroxyapatite particles to promote osteoblast viability and antibacterial activity. Biomed. Mater. 12 (3), 035006. doi:10.1088/1748-605X/aa6c8d

Shkodenko, L., Kassirov, I., and Koshel, E. (2020). Metal oxide nanoparticles against bacterial biofilms: perspectives and limitations. Microorganisms 8 (10), 1545. doi:10.3390/microorganisms 8101545

Shrestha, B. K., Shrestha, S., Tiwari, A. P., Kim, J. I., Ko, S. W., Kim, H. J., et al. (2017). Bio-inspired hybrid scaffold of zinc oxide-functionalized multi-wall carbon nanotubes reinforced polyurethane nanofibers for bone tissue engineering. Mater. Des. 133, 69-81. doi:10.1016/j.matdes.2017.07.049

Shuai, C., Guo, W., Wu, P., Yang, W., Hu, S., Xia, Y., et al. (2018). A graphene oxide-Ag co-dispersing nanosystem: dual synergistic effects on antibacterial activities and mechanical properties of polymer scaffolds. Chem. Eng. J. 347, 322-333. doi:10.1016/j.cej.2018.04.092

Shuai, C., Huang, W., Feng, P., Gao, C., Gao, D., Deng, Y., et al. (2017). Nanodiamond reinforced polyvinylidene fluoride/bioglass scaffolds for bone tissue engineering. J. Porous Mater. 24 (1), 249-255. doi:10.1007/s10934-016-0258-0

Shuai, C., Li, Y., Wang, G., Yang, W., Peng, S., and Feng, P. (2019). Surface modification of nanodiamond: toward the dispersion of reinforced phase in poly-l-lactic acid scaffolds. Int. J. Biol. Macromol. 126, 1116-1124. doi:10.1016/ j.ijbiomac.2019.01.004

Singariya, P., Mourya, K. K., and Kumar, P. (2012). Antimicrobial activity of the crude extracts of Withania somnifera and cenchrus setigerus in-vitro. Phcog. J. 4 (27), 60-65. doi:10.5530/pj.2012.27.10

Sirelkhatim, A., Mahmud, S., Seeni, A., Kaus, N. H. M., Ann, L. C., Bakhori, S. K. M., et al. (2015). Review on zinc oxide nanoparticles: antibacterial activity and toxicity mechanism. Nano-Micro Lett. 7 (3), 219-242. doi:10.1007/s40820-0150040-x

Song, G., Guo, X., Zong, X., Du, L., Zhao, J., Lai, C., et al. (2019). Toxicity of functionalized multi-walled carbon nanotubes on bone mesenchymal stem cell in rats. Dent. Mater. J. 38 (1), 127-135. doi:10.4012/dmj.2017-313

Soumya, S., Sajesh, K. M., Jayakumar, R., Nair, S. V., and Chennazhi, K. P. (2012). Development of a phytochemical scaffold for bone tissue engineering using Cissus quadrangularis extract. Carbohydr. Polym. 87 (2), 1787-1795. doi:10. 1016/j.carbpol.2011.09.094

Sruthi, R., Balagangadharan, K., and Selvamurugan, N. (2020). Polycaprolactone/ polyvinylpyrrolidone coaxial electrospun fibers containing veratric acid-loaded chitosan nanoparticles for bone regeneration. Colloids Surf. B Biointerfaces. 20, 111110. doi:10.1016/j.colsurfb.2020.111110

Stanić, V., Dimitrijević, S., Antić-Stanković, J., Mitrić, M., Jokić, B., Plećaš, I. B., et al. (2010). Synthesis, characterization and antimicrobial activity of copper and zinc-doped hydroxyapatite nanopowders. Appl. Surf. Sci. 256 (20), 6083-6089. doi:10.1016/j.matchemphys.2012.04.005

Stanić, V., Janaćković, D., Dimitrijević, S., Tanasković, S. B., Mitrić, M., Pavlović, M. S., et al. (2011). Synthesis of antimicrobial monophase silver-doped hydroxyapatite nanopowders for bone tissue engineering. Appl. Surf. Sci. 257 (9), 4510-4518. doi:10.1016/j.apsusc.2010.12.113

Su, L. C., Xie, Z., Zhang, Y., Nguyen, K. T., and Yang, J. (2014). Study on the antimicrobial properties of citrate-based biodegradable polymers. Front. Bioeng. Biotechnol. 2, 23. doi:10.3389/fbioe.2014.00023

Suliman, S., Sun, Y., Pedersen, T. O., Xue, Y., Nickel, J., Waag, T., et al. (2016). In vivo host response and degradation of copolymer scaffolds functionalized with nanodiamonds and bone morphogenetic protein 2. Adv. Healthc. Mater. 5 (6), 730-742. doi:10.1002/adhm.201500723

Šupová, M. (2015). Substituted hydroxyapatites for biomedical applications: a review. Ceram. Int. 41 (8), 9203-9231. doi:10.1016/j.ceramint.2015.03.316

Suvarna, V., Sarkar, M., Chaubey, P., Khan, T., Sherje, A., Patel, K., et al. (2018). Bone health and natural products-an insight. Front. Pharmacol. 9, 981. doi:10. 3389/fphar.2018.00981

Swarnkar, G., Sharan, K., Siddiqui, J. A., Chakravarti, B., Rawat, P., Kumar, M., et al. (2011). A novel flavonoid isolated from the steam-bark of Ulmus Wallichiana Planchon stimulates osteoblast function and inhibits osteoclast and adipocyte differentiation. Eur. J. Pharmacol. 658 (2-3), 65-73. doi:10.1016/j.ejphar.2011.02.032 
Swarnkar, G., Sharan, K., Siddiqui, J. A., Mishra, J. S., Khan, K., Khan, M. P., et al. (2012). A naturally occurring naringenin derivative exerts potent bone anabolic effects by mimicking oestrogen action on osteoblasts. Br. J. Pharmacol. 165 (5), 1526-1542. doi:10.1111/j.1476-5381.2011.01637.x

Tamburaci, S., Kimna, C., and Tihminlioglu, F. (2018). Novel phytochemical Cissus quadrangularis extract-loaded chitosan/Na-carboxymethyl cellulose-based scaffolds for bone regeneration. J. Bioact. Compat Polym. 33 (6), 629-646. doi:10.1177/0883911518793913

Tan, F., Liu, J., Song, K., Liu, M., and Wang, J. (2018). Effect of surface charge on osteoblastic proliferation and differentiation on a poly (ethylene glycol)diacrylate hydrogel. J. Mater. Sci. 53 (2), 908-920. doi:10.1007/s10853-0171558-8

Taneja, I., Raghuvanshi, A., Raju, K. S. R., Awasthi, P., Rashid, M., Singh, S., et al. (2020). Bioavailability, tissue distribution and excretion studies of a potential anti-osteoporotic agent, medicarpin, in female rats using validated LC-MS/MS method. J. Pharmaceut. Biomed. Anal. 180, 112978. doi:10.1016/j.jpba.2019. 112978

Tao, B., Chen, M., Lin, C., Lu, L., Yuan, Z., Liu, J., et al. (2019). Zn-incorporation with graphene oxide on Ti substrates surface to improve osteogenic activity and inhibit bacterial adhesion. J. Biomed. Mater. Res. 107 (10), 2310-2326. doi:10. 1002/jbm.a. 36740

Tavakolian, M., Jafari, S. M., and van de Ven, T. G. (2020). A review on surfacefunctionalized cellulosic nanostructures as biocompatible antibacterial materials. Nano-Micro Lett. 12 (1), 1-23. doi:10.1007/s40820-020-0408-4

Thian, E. S., Konishi, T., Kawanobe, Y., Lim, P. N., Choong, C., Ho, B., et al. (2013). Zinc-substituted hydroxyapatite: a biomaterial with enhanced bioactivity and antibacterial properties. J. Mater. Sci. Mater. Med. 24 (2), 437-445. doi:10.1007/ s10856-012-4817-x

Thongtham, N., Chai-in, P., Unger, O., Boonrungsiman, S., and Suwantong, O. (2020). Fabrication of chitosan/collagen/hydroxyapatite scaffolds with encapsulated Cissus quadrangularis extract. Polym. Adv. Technol. doi:10. $1002 /$ pat.4879

Thukkaram, M., Sitaram, S., and Subbiahdoss, G. (2014). Antibacterial efficacy of iron-oxide nanoparticles against biofilms on different biomaterial surfaces. Int. J. Biomater. 71, 608-613. doi:10.1155/2014/716080

Tohidlou, H., Shafiei, S. S., Abbasi, S., Asadi-Eydivand, M., and Fathi-Roudsari, M. (2019). Amine-functionalized single-walled carbon nanotube/polycaprolactone electrospun scaffold for bone tissue engineering: in vitro study. Fibers Polym. 20 (9), 1869-1882. doi:10.1007/s12221-019-1262-1

Tomoaia, G., Mocanu, A., Vida-Simiti, I., Jumate, N., Bobos, L. D., Soritau, O., et al. (2014). Silicon effect on the composition and structure of nanocalcium phosphates: in vitro biocompatibility to human osteoblasts. Mater. Sci. Eng. C. 37, 37-47. doi:10.1016/j.msec.2013.12.027

Tsimbouri, P. M., Fisher, L., Holloway, N., Sjostrom, T., Nobbs, A. H., Meek, R. D., et al. (2016). Osteogenic and bactericidal surfaces from hydrothermal titania nanowires on titanium substrates. Sci. Rep. 6, 36857. doi:10.1038/srep36817

Turcheniuk, V., Raks, V., Issa, R., Cooper, I. R., Cragg, P. J., Jijie, R., et al. (2015). Antimicrobial activity of menthol modified nanodiamond particles. Diam. Relat. Mater. 57, 2-8. doi:10.1016/j.diamond.2014.12.002

Tyagi, A. M., Gautam, A. K., Kumar, A., Srivastava, K., Bhargavan, B., Trivedi, R., et al. (2010). Medicarpin inhibits osteoclastogenesis and has nonestrogenic bone conserving effect in ovariectomized mice. Mol. Cell. Endocrinol. 325 (1-2), 101-109. doi:10.1016/j.mce.2010.05.016

Uskoković, V., Iyer, M. A., and Wu, V. M. (2017). One ion to rule them all: the combined antibacterial, osteoinductive and anticancer properties of selenite-incorporated hydroxyapatite. J. Mater. Chem. B. 5 (7), 1430-1445. doi:10.1039/c6tb03387c

Vallet-Regí, M., Lozano, D., González, B., and Izquierdo-Barba, I. (2020). Biomaterials against bone infection. Adv. Healthc. Mater. 56, 729-830. doi:10.1002/adhm.202000310

Vandecandelaere, I., Van Acker, H., and Coenye, T. (2016). A microplate-based system as in vitro model of biofilm growth and quantification, bacterial persistence. New York, NY: Humana Press, 53-66. doi:10.1007/978-1-4939-2854-5_5

Varier, K. M., Gudeppu, M., Chinnasamy, A., Thangarajan, S., Balasubramanian, J., Li, Y., et al. (2019). Advanced nanostructured materials for environmental remediation. Nanoparticles: antimicrobial applications and its prospects. Cham: Springer, 321-355. doi:10.1007/978-3-030-04477-0_12

Verma, A., Arshad, F., Ahmad, K., Goswami, U., Samanta, S. K., Sahoo, A. K., et al. (2019). Role of surface charge in enhancing antibacterial activity of fluorescent carbon dots. Nanotechnology 31 (9), 095101. doi:10.1088/1361$6528 / a b 55 b 8$

Voss, G. T., Gularte, M. S., Vogt, A. G., Giongo, J. L., Vaucher, R. A., Echenique, J. V., et al. (2018). Polysaccharide-based film loaded with vitamin $\mathrm{C}$ and propolis: a promising device to accelerate diabetic wound healing. Int. J. Pharmaceut. 552 (1-2), 340-351. doi:10.1016/j.ijpharm. 2018.10.009

Vu, A. A., and Bose, S. (2019). Effects of vitamin D 3 release from 3D printed calcium phosphate scaffolds on osteoblast and osteoclast cell proliferation for bone tissue engineering. RSC Adv. 9 (60), 34847-34853. doi:10.1039/C9RA06630F

Vukomanović, M., Logar, M., Škapin, S. D., and Suvorov, D. (2014). Hydroxyapatite/gold/arginine: designing the structure to create antibacterial activity. J. Mater. Chem. B. 2 (11), 1557-1564. doi:10.1039/C3TB21612H

Wang, Q., Chen, C., Liu, W., He, X., Zhou, N., Zhang, D., et al. (2017). Levofloxacin loaded mesoporous silica microspheres/nanohydroxyapatite/polyurethane composite scaffold for the treatment of chronic osteomyelitis with bone defects. Sci. Rep. 7 (1), 1-13. doi:10. 1038/srep41808

Wang, B., Yang, M., Liu, L., Yan, G., Yan, H., Feng, J., et al. (2019a). Osteogenic potential of $\mathrm{Zn} \mathrm{2+-passivated} \mathrm{carbon} \mathrm{dots} \mathrm{for} \mathrm{bone} \mathrm{regeneration} \mathrm{in} \mathrm{vivo.}$ Biomater. Sci. 7 (12), 5414-5423. doi:10.1039/C9BM01181A

Wang, H., Song, Z., Gu, J., Li, S., Wu, Y., and Han, H. (2019b). Nitrogen-doped carbon quantum dots for preventing biofilm formation and eradicating drugresistant bacteria infection. ACS Biomater. Sci. Eng. 5 (9), 4739-4749. doi:10. 1021/acsbiomaterials.9b00583

Wang, W., Huang, B., Byun, J. J., and Bártolo, P. (2019c). Assessment of PCL/ carbon material scaffolds for bone regeneration. J. Mech. Behav. Biomed. Mater. 93, 52-60. doi:10.1016/j.jmbbm.2019.01.020

Wang, X., Ihara, S., Li, X., Ito, A., Sogo, Y., Watanabe, Y., et al. (2019d). Sidoping increases the adjuvant activity of hydroxyapatite nanorods. Colloids Surf. B Biointerfaces 174, 300-307. doi:10.1016/j.colsurfb. 2018.11.026

Wang, N., Fuh, J. Y. H., Dheen, S. T., and Senthil Kumar, A. (2020). Functions and applications of metallic and metallic oxide nanoparticles in orthopedic implants and scaffolds. J. Biomed. Mater. Res. B Appl. Biomater. 34, 668. doi:10.1002/jbm. b. 34688

Wehling, J., Dringen, R., Zare, R. N., Maas, M., and Rezwan, K. (2014). Bactericidal activity of partially oxidized nanodiamonds. ACS Nano. 8 (6), 6475-6483. doi: $10.1021 / \mathrm{nn} 502230 \mathrm{~m}$

Weng, W., Nie, W., Zhou, Q., Zhou, X., Cao, L., Ji, F., et al. (2017). Controlled release of vancomycin from $3 \mathrm{D}$ porous graphene-based composites for dualpurpose treatment of infected bone defects. RSC $A d v .7$ (5), 2753-2765. doi:10. 1039/C6RA26062D

Winkler, Heinz. (2017). Treatment of chronic orthopaedic infection. EFORT Open Rev. 2 (5), 110-116. doi:10.1302/2058-5241.2.160063

Witso, E. (2014). "Infections in orthopaedics and fractures," in European surgical orthopaedics and traumatology. Editor G. Bentley (Berlin, Heidelberg: Springer). doi:10.1007/978-3-642-34746-7_17

Wu, C., Zhou, Y., Xu, M., Han, P., Chen, L., Chang, J., et al. (2013). Coppercontaining mesoporous bioactive glass scaffolds with multifunctional properties of angiogenesis capacity, osteostimulation and antibacterial activity. Biomaterials 34 (2), 422-433. doi:10.1016/j.biomaterials.2012.09.066

Wu, S., Zuber, F., Maniura-Weber, K., Brugger, J., and Ren, Q. (2018). Nanostructured surface topographies have an effect on bactericidal activity. J. Nanobiotechnol. 16 (1), 20. doi:10.1186/s12951-018-0347-0

Wu, X., Bruschi, M., Waag, T., Schweeberg, S., Tian, Y., Meinhardt, T., et al. (2017). Functionalization of bone implants with nanodiamond particles and angiopoietin-1 to improve vascularization and bone regeneration. J. Mater. Chem. B. 5 (32), 6629-6636. doi:10.1039/C7TB00723J

Xie, H., Cao, T., Franco-Obregón, A., and Rosa, V. (2019). Graphene-induced osteogenic differentiation is mediated by the integrin/FAK axis. Int. J. Mol. Sci. 20 (3), 574. doi:10.3390/ijms20030574

Xie, H., Wang, J., Li, C., Gu, Z., Chen, Q., and Li, L. (2013). Application of strontium doped calcium polyphosphate bioceramic as scaffolds for bone tissue engineering. Ceram. Int. 39 (8), 8945-8954. doi:10.1016/j.ceramint.2013.04.091

Xie, H., Wang, Q., Ye, Q., Wan, C., and Li, L. (2012). Application of K/Sr co-doped calcium polyphosphate bioceramic as scaffolds for bone substitutes. J. Mater. Sci. Mater. Med. 23 (4), 1033-1044. doi:10.1007/s10856-012-4556-Z 
Yahia, I. S., Shkir, M., AlFaify, S., Ganesh, V., Zahran, H. Y., and Kilany, M. (2017). Facile microwave-assisted synthesis of Te-doped hydroxyapatite nanorods and nanosheets and their characterizations for bone cement applications. Mater. Sci. Eng. C. 72, 472-480. doi:10.1016/j.msec.2016. 11.074

Yamaguchi, M. (2010). Role of nutritional zinc in the prevention of osteoporosis. Mol. Cell. Biochem. 338 (1-2), 241-254. doi:10.1007/s11010-009-0358-0

Yamaguchi, M. (1998). Role of zinc in bone formation and bone resorption. J. Trace Elem. Exp. Med. 11 (2-3), 119-135. doi:10.1002/(SICI)1520-670X(1998)11:2/ $3<119::$ AID-JTRA5 $>3.0$. CO;2-3

Yan, C., Zhang, S., Wang, C., and Zhang, Q. (2019). A fructooligosaccharide from Achyranthes bidentata inhibits osteoporosis by stimulating bone formation. Carbohydr. Polym. 210, 110-118. doi:10.1016/j.carbpol.2019.01.026

Yang, L., Gao, Q., Ge, L., Zhou, Q., Warszawik, E. M., Bron, R., et al. (2020). Topography induced stiffness alteration of stem cells influences osteogenic differentiation. Biomater. Sci. 8 (9), 2638-2652. doi:10.1039/ D0BM00264J

Yang, M., and Zhang, M. (2019). Biodegradation of carbon nanotubes by macrophages. Front. Mater. 6, 225. doi:10.3389/fmats.2019.00225

Yassin, M. A., Mustafa, K., Xing, Z., Sun, Y., Fasmer, K. E., Waag, T., et al. (2017). A copolymer scaffold functionalized with nanodiamond particles enhances osteogenic metabolic activity and bone regeneration. Macromol. Biosci. 17 (6), 1600427. doi:10.1002/mabi.201600427

Yoon, I. K., Hwang, J. Y., Seo, J. W., Jang, W. C., Kim, H. W., and Shin, U. S. (2014). Carbon nanotube-gelatin-hydroxyapatite nanohybrids with multilayer core-shell structure for mimicking natural bone. Carbon. 77, 379-389. doi:10.1016/j.carbon.2014.05.041

Yu, L., Jin, G., Ouyang, L., Wang, D., Qiao, Y., and Liu, X. (2016). Antibacterial activity, osteogenic and angiogenic behaviors of copper-bearing titanium synthesized by PIII\&D. J. Mater. Chem. B 4 (7), 1296-1309. doi:10.1039/ C5TB02300A

Yun'an Qing, L. C., Li, R., Liu, G., Zhang, Y., Tang, X., Wang, J., et al. (2018). Potential antibacterial mechanism of silver nanoparticles and the optimization of orthopedic implants by advanced modification technologies. Int. J. Nanomed. 13, 3311. doi:10.2147/IJN.S165125

Zambrano, L. M., Brandao, D. A., Rocha, F. R., Marsiglio, R. P., Longo, I. B., Primo, F. L., et al. (2018). Local administration of curcumin-loaded nanoparticles effectively inhibits inflammation and bone resorption associated with experimental periodontal disease. Sci. Rep. 8 (1), 1-11. doi:10.1038/s41598018-24866-2

Zardini, H. Z., Amiri, A., Shanbedi, M., Maghrebi, M., and Baniadam, M. (2012). Enhanced antibacterial activity of amino acids-functionalized multi walled carbon nanotubes by a simple method. Colloids Surf. B Biointerfaces 92, 196-202. doi:10.1016/j.colsurfb.2011.11.045

Zardini, H. Z., Davarpanah, M., Shanbedi, M., Amiri, A., Maghrebi, M., and Ebrahimi, L. (2014). Microbial toxicity of ethanolamines-multiwalled carbon nanotubes. J. Biomed. Mater. Res. 102 (6), 1774-1781. doi:10. 1002/jbm.a.34846

Zeeshan, R., Mutahir, Z., Iqbal, H., Ali, M., Iqbal, F., Ijaz, K., et al. (2018). Hydroxypropylmethyl cellulose (HPMC) crosslinked chitosan (CH) based scaffolds containing bioactive glass $(\mathrm{BG})$ and zinc oxide $(\mathrm{ZnO})$ for alveolar bone repair. Carbohydr. Polym. 193, 9-18. doi:10.1016/j.carbpol.2018. 03.046
Zhang, J., Doll, B. A., Beckman, E. J., and Hollinger, J. O. (2003). A biodegradable polyurethane-ascorbic acid scaffold for bone tissue engineering. J. Biomed. Mater. Res. Part A Off. J. Soc. Biomater. 67 (2), 389-400. doi:10.1002/jbm.a.10015

Zhang, R., Hu, S. J., Li, C., Zhang, F., Gan, H. Q., and Mei, Q. B. (2012). Achyranthes bidentata root extract prevent OVX-induced osteoporosis in rats. J. Ethnopharmacol. 139 (1), 12-18. doi:10.1016/j.jep.2011.05.034

Zhang, S., Zhang, Q., Zhang, D., Wang, C., and Yan, C. (2018a). Antiosteoporosis activity of a novel Achyranthes bidentata polysaccharide via stimulating bone formation. Carbohydr. Polym. 184, 288-298. doi:10.1016/j. carbpol.2017.12.070

Zhang, X., Yin, X., Luo, J., Zheng, X., Wang, H., Wang, J., et al. (2018b). Novel hierarchical nitrogen-doped multiwalled carbon nanotubes/cellulose/ nanohydroxyapatite nanocomposite as an osteoinductive scaffold for enhancing bone regeneration. ACS Biomater. Sci. Eng. 5 (1), 294-307. doi:10.1021/acsbiomaterials.8b00908

Zhang, L. Y., Fang, Z. H., Li, Q. L., and Cao, C. Y. (2019). A tooth-binding antimicrobial peptide to prevent the formation of dental biofilm. J. Mater. Sci. Mater. Med. 30 (4), 45. doi:10.1007/s10856-019-6246-6

Zhang, F., Zhou, M., Gu, W., Shen, Z., Ma, X., Lu, F., et al. (2020a). Zinc-/coppersubstituted dicalcium silicate cement: advanced biomaterials with enhanced osteogenesis and long-term antibacterial properties. J. Mater. Chem. B. 8 (5), 1060-1070. doi:10.1039/C9TB02691F

Zhang, R., Han, S., Ren, N., Liang, L., Liang, N., Liu, F., et al. (2020b). Topographical regulation of stem cell differentiation by plant-derived micro/ nanostructures. Nanoscale. doi:10.1039/D0NR02765K

Zheng, K., Lu, M., Rutkowski, B., Dai, X., Yang, Y., Taccardi, N., et al. (2016). ZnO quantum dots modified bioactive glass nanoparticles with $\mathrm{pH}$-sensitive release of $\mathrm{Zn}$ ions, fluorescence, antibacterial and osteogenic properties. J. Mater. Chem. B. 4 (48), 7936-7949. doi:10.1039/C6TB02053D

Zhou, X., He, J., and Zhou, C. (2019). Strategies from nature: polycaprolactonebased mimetic antimicrobial peptide block copolymers with low cytotoxicity and excellent antibacterial efficiency. Polym. Chem. 10 (8), 945-953. doi:10. 1039/C8PY01394B

Zhou, Z., Pan, C., Lu, Y., Gao, Y., Liu, W., Yin, P., et al. (2017). Combination of erythromycin and curcumin alleviates Staphylococcus aureus induced osteomyelitis in rats. Fronti. Cell. Infect. Microbiol. 7, 379. doi:10.3389/ fcimb.2017.00379

Zhu, L., Luo, D., and Liu, Y. (2020). Effect of the nano/microscale structure of biomaterial scaffolds on bone regeneration. Int. J. Oral Sci. 12 (1), 1-15. doi:10. 1038/s41368-020-0073-y

Conflict of Interest: The authors declare that the research was conducted in the absence of any commercial or financial relationships that could be construed as a potential conflict of interest.

Copyright $\odot 2021$ Preethi and Bellare. This is an open-access article distributed under the terms of the Creative Commons Attribution License (CC BY). The use, distribution or reproduction in other forums is permitted, provided the original author(s) and the copyright owner(s) are credited and that the original publication in this journal is cited, in accordance with accepted academic practice. No use, distribution or reproduction is permitted which does not comply with these terms. 


\section{GLOSSARY}

$\uparrow$ Increase

$\downarrow$ decrease

A Adhesion

ADSC Adipose derived stem cell

ALP Alkaline phosphatase

AMP Anti-microbial peptide

Ang Angiogenesis

BMP-2 Bone morphogenic protein-2

BMSC Bone marrow derived MSC

BV Bone volume

CD Carbon dot

CFU Colony forming units

CNT Carbon nanotube

Col-I Collagen I

HA Hydroxyapatite

L132 Human cervix carcinoma cells

M Mineralization

MC3T3-E1 Osteoblast precursor cell line from mouse

MG63, SaOS-2, U-2 OS Different osteosarcoma derived cells

MIC Minimum inhibition concentration
MRSA Methicillin-resistant S. aureus

MSC Mesenchymal stem cell

MW Multiwall

ND Nanodiamond

OB Osteoblast

OC Osteoclast

OD Osteogenic differentiation

P Proliferation

PCL Poly( $\varepsilon$-caprolactone)

PEEK Polyetheretherketone

PEG Polyethylene glycol

PGA Poly glycolicacid

PLCL Poly (lactide -co- caprolactone)

PLLA Poly(l-lactic acid)

PLGA Poly (lactic -co- glycolic acid)

PMMA Polymethyl methacrylate

PU Polyurethane

PVA Polyvinyl alcohol

PVDF Polyvinylidene fluoride

PVP Polyvinylpyrrolidone

S Solubility

SW Single wall 